\title{
Make Trade Not War?
}

\author{
PHILIPPE MARTIN \\ University of Paris 1 Pantheon-Sorbonne, \\ Paris School of Economics, and Centre for Economic Policy Research \\ THIERRY MAYER \\ University of Paris 1 Pantheon-Sorbonne, \\ Paris School of Economics, CEPII, and Centre for Economic Policy Research \\ and \\ MATHIAS THOENIG \\ University of Geneva and Paris School of Economics
}

First version received April 2006; final version accepted November 2007 (Eds.)

\begin{abstract}
This paper analyses theoretically and empirically the relationship between military conflicts and trade. We show that the conventional wisdom that trade promotes peace is only partially true even in a model where trade is economically beneficial, military conflicts reduce trade, and leaders are rational. When war can occur because of the presence of asymmetric information, the probability of escalation is lower for countries that trade more bilaterally because of the opportunity cost associated with the loss of trade gains. However, countries more open to global trade have a higher probability of war because multilateral trade openness decreases bilateral dependence to any given country and the cost of a bilateral conflict. We test our predictions on a large data set of military conflicts on the 1950-2000 period. Using different strategies to solve the endogeneity issues, including instrumental variables, we find robust evidence for the contrasting effects of bilateral and multilateral trade openness. For proximate countries, we find that trade has had a surprisingly large effect on their probability of military conflict.
\end{abstract}

\section{INTRODUCTION}

The natural effect of trade is to bring about peace. Two nations which trade together, render themselves reciprocally dependent; for if one has an interest in buying, the other has an interest in selling; and all unions are based upon mutual needs. (Montesquieu, De l'esprit des Lois, 1758).

I will never falter in my belief that enduring peace and the welfare of nations are indissolubly connected with friendliness, fairness, equality, and the maximum practicable degree of freedom in international trade." (Cordell Hull, U.S. secretary of state, 1933-1944).

Does globalization pacify international relations? The "liberal" view in political science argues that increasing trade flows and the spread of free markets and democracy should limit the incentive to use military force in interstate relations. This vision, which can partly be traced back to Kant's Essay on Perpetual Peace (1795), has been very influential: The main objective of the European trade integration process was to prevent the killing and destruction of the two World Wars from ever happening again. ${ }^{1}$ Figure 1

1. Before this, the 1860 Anglo-French commercial treaty was signed to diffuse tensions between the two countries. Outside Europe, MERCOSUR was created in 1991 in part to curtail the military power in Argentina and Brazil and then two recent and fragile democracies with potential conflicts over natural resources. 


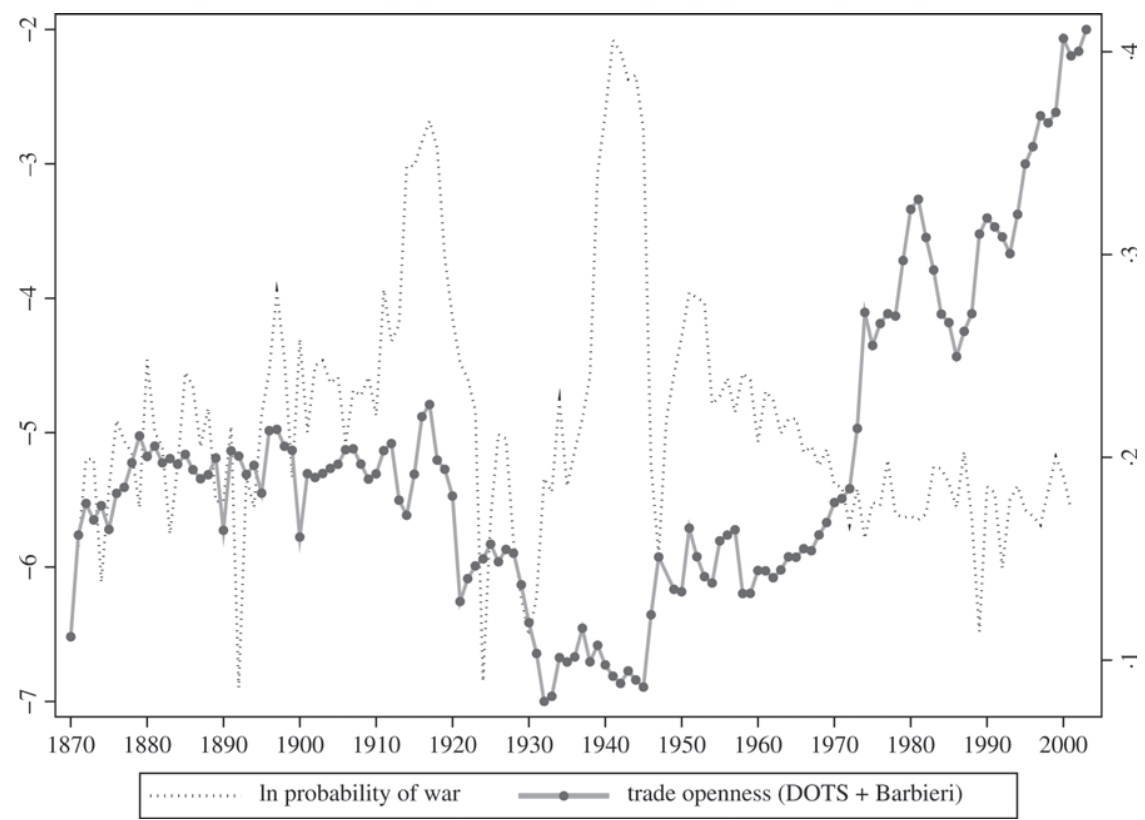

FIGURE 1

Militarized conflict probability and trade openness over time

suggests $^{2}$ however, that during the 1870-2001 period, the correlation between trade openness and military conflicts is not a clear cut one. The first era of globalization, at the end of the 19th century, was a period of rising trade openness and multiple military conflicts, culminating with World War I. Then, the interwar period was characterized by a simultaneous collapse of world trade and conflicts. After World War II, world trade increased rapidly, while the number of conflicts decreased (although the risk of a global conflict was obviously high). There is no clear evidence that the 1990s, during which trade flows increased dramatically, was a period of lower prevalence of military conflicts, even taking into account the increase in the number of sovereign states.

The objective of this paper is to shed light on the following question: If trade promotes peace as suggested by the European example, why is it that globalization, interpreted as trade liberalization at the global level, has not lived up to its promise of decreasing the prevalence of violent interstate conflicts? We offer a theoretical and empirical answer to this question. On the theoretical side, we build a framework where escalation to military conflicts may occur because of the failure of negotiations in a bargaining game. The structure of this game is fairly general: (1) war is Pareto dominated by peace, (2) countries have private information, and (3) countries can choose any type of negotiation protocol. We then embed this game in a standard new trade theory model. We show that a pair of countries with more bilateral trade has a lower probability of bilateral war. However, multilateral trade openness has the opposite effect: Any pair of countries more open with the rest of the world decreases its degree of bilateral dependence and its cost of a

2. Figure 1 depicts the occurrence of militarized interstate disputes (MIDs) between country pairs divided by the total number of country pairs. Figure 1 accounts for events characterized by display of force, use of force, and military conflicts with at least 1000 deaths of military personnel. See Section 3.1 for a more precise description of the data. Trade openness is the sum of world trade (exports and imports) divided by world GDP (trade data come from the International Monetary Fund (IMF) Direction of Trade Statistics (DOTS) data set and Barbieri (2002) while GDP figures come from the World Bank's World Development Indicators (WDI) and Maddison (2001) for historical data). 
bilateral conflict, and this results in a higher probability of bilateral war. A theoretical prediction of our model is that globalization of trade flows changes the nature of conflicts. It decreases the probability of global conflicts (maybe the most costly in terms of human welfare) but increases the probability of any bilateral conflict. The reason for the second result is that globalization decreases the bilateral dependence for any country pair, and this weakens the incentive to make concessions in order to avoid the escalation of a dispute into a bilateral military conflict. This is especially true for countries with a high probability of dispute with a local dimension such as disputes on borders, resources, and ethnic minorities.

We test the theoretical prediction that bilateral and multilateral trade have opposite effects on the probability of bilateral military conflicts on the 1950-2000 period using a data set from the Correlates of War (COW) project that makes available a very precise description of interstate armed conflicts. The mechanism at work in our theoretical model rests on the hypothesis that the absence of peace disrupts trade and therefore puts trade gains at risk. We first test this hypothesis. Using a gravity-type model of trade, we find that bilateral trade costs indeed increase significantly with a bilateral conflict. However, multilateral trade costs do not increase significantly. Second, we test the predictions of the model related to the contradictory effects of bilateral and multilateral trade on conflict. We address the endogeneity issue by controlling for various codeterminants of conflict and trade; by including country pair fixed effects and time effects; and, finally, by implementing an instrumental variable strategy. Our results are robust to these different estimation strategies. The quantitative impact of trade is surprisingly large for proximate countries (those with a bilateral distance less than $1000 \mathrm{~km}$ ), those for which the probability of a conflict is the highest. We estimate the quantitative effect of the globalization process of the past 30 years that is characterized by expansion of both bilateral trade flows (with a negative impact on the probability of conflict) and multilateral trade flows (with a positive impact on this probability). We find that its net effect has been to increase the probability of a bilateral conflict by around $20 \%$ for proximate countries. However, for more distant countries, the effect of globalization on their bilateral relation has been very small. This fits well with the stylized fact depicted by Figure 2. This strongly suggests that conflicts have become more localized over time as the average distance between two countries in military conflict has been halved during the 1950-2000 period. It is consistent with the changing nature of war as discussed by historians (Keegan, 1984; Bond, 1986; Van Creveld, 1991).

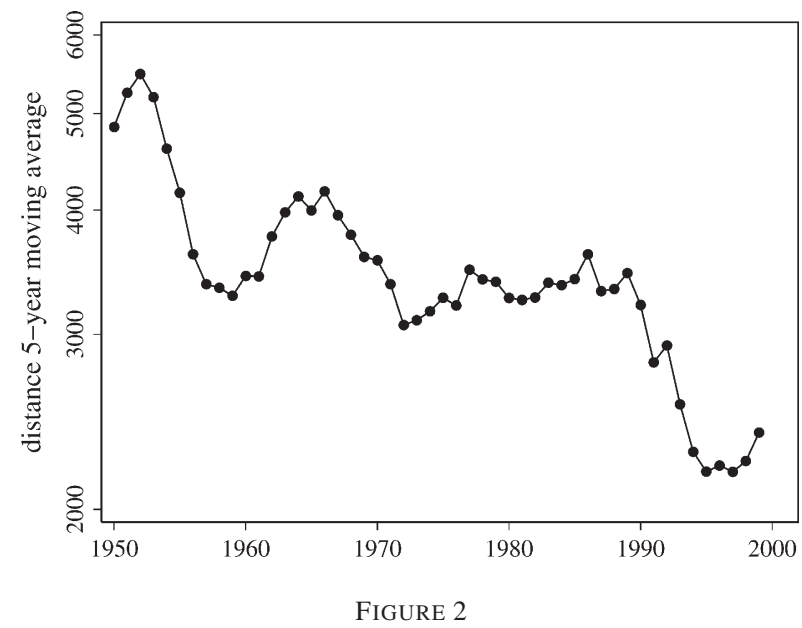

Average distance of militarized conflicts over time

(C) 2008 The Review of Economic Studies Limited 
The related literature ranges from political science to political economy. The question of the impact of trade on war is an old and a controversial one among political scientists (see Barbieri and Schneider, 1999; Kapstein, 2003, for recent surveys). From a theoretical point of view, the main debate is between the "trade promotes peace" liberal school and the neo-Marxist school which argues that asymmetric trade links lead to conflicts. The main difference between these two positions comes from the opposing view they have on the possibility of gains from trade for all countries involved. From an empirical point of view, recent studies in political science test the impact of bilateral trade (in different forms) on the frequency of war between country pairs. Many find a negative relationship (see, e.g. Polachek, 1980; Mansfield, 1995; Polachek, Robst and Chang, 1999; Oneal and Russet, 1999). However, some recent studies have found a positive relationship (see Barbieri, 1996, 2002). These papers, however, do not test models in which trade and war are both endogenous. ${ }^{3}$ In economics, related empirical papers on the issue are recent papers by Blomberg and Hess (2006) and Glick and Taylor (2005). They, however, focus on the reverse causal link, that is on the effect of war on trade. They control for the standard determinants of trade as used in the gravity equation literature. To our knowledge, our paper is, however, the first to derive theoretically the two-sided effect of trade on peace (positive for bilateral trade and negative for multilateral trade) and to empirically test this prediction.

Skaperdas and Syropoulos $(2001,2002)$ show in a theoretical model that terms of trade effects may intensify conflict over resources, a mechanism from which we abstract in the theoretical model. We also abstract from internal conflicts between factors of production that may be generated by opening to trade as in Schneider and Schulze (2005). The recent literature on the number and size of countries (see Alesina and Spolaore, 1997, 2003) has also clear connections with our paper because in both frameworks, a key mechanism is that globalization reduces local economic dependence. In Alesina and Spolaore, the consequence is an increase in the equilibrium number of countries. In our framework, it decreases the opportunity cost of conflict and increases the equilibrium number of local wars. Alesina and Spolaore $(2005,2006)$ also study the link between conflicts, defence spending, and the number of countries. Their model aims to explain how a decrease in international conflicts can be associated with an increase in localized conflicts between a higher number of smaller countries. Their explanation is the following: When international conflicts become less frequent, the advantages of large countries (in terms of provision of public and defence goods) weaken so that countries split and the number of countries increases. This itself leads to an increase in the number of (localized) conflicts. In our paper, the number and size of countries are exogenous but trade and the probability of escalation to war are endogenous.

The next section derives the theoretical probability of escalation to war between two countries as a function of the degree of asymmetric information, bilateral and multilateral trade, and analyses the ambiguous impact of trade on peace. Section 3 first quantifies the impact of war on both bilateral and multilateral trade and then tests the impact of trade openness, bilateral and multilateral, on the probability of military conflicts between countries.

\section{THE THEORY}

In this section, we analyse a simple model of negotiation and escalation to war. We then embed it in a model of trade to assess the marginal impact of trade on war.

3. The list of controls included are those most cited in the political science literature (democratic level, military capabilities, etc.) but rarely include determinants of trade that could also affect the probability of war. For example, Barbieri $(1996,2002)$ does not include distance as one of her controls even though it is well known that bilateral distance affects very negatively both bilateral trade and the probability of conflicts (Kocs, 1995). 


\subsection{Escalation to war under asymmetric information}

We follow the rationalist view of war among political scientists (Fearon, 1995; Powell, 1999, for surveys) and economists (Grossman, 2003) whose aim is to explain the puzzle that wars do occur despite their costs, even in the presence of rational leaders. The rationalist view is the most natural structure for our argument because trade gains are then taken into account in the decision to go to war. ${ }^{4}$

Studies in the rationalist view of war, however, greatly differ with respect to their assumptions on institutional setting and the negotiation protocols. In this paper, the only institutional constraint we impose is that the negotiation protocol (bilateral or multilateral negotiations, repeated stages, etc.) chosen is the one that maximizes the ex ante welfare of both countries. This more general view has two advantages. First, it avoids the main drawback of the existing literature, namely the high sensitivity of results to the underlying restrictions made on institutions. Second, it is fully consistent with the rationalist school view of war, as rationality implies that leaders choose the most efficient institutional setting and negotiation protocol.

We assume that wars can occur because disputes may escalate into a military conflict. In our model, disputes are exogenous but the probability of escalation is endogenous. Consider two countries $i$ and $j$. Disputes on how to share the surplus under peace may arise between these two countries. They can end peacefully if countries succeed through a negotiated settlement or can escalate into military conflict if negotiations fail. The timing of the game is the following: A negotiation protocol is optimally chosen; then, information is privately revealed and negotiations take place. War occurs or not depending on the outcome of negotiations. Production, trade, and consumption are then realized as described in the next section.

Leaders in both countries care about the utility level of a representative agent of their own country who, in peace, obtains, respectively, $\left(U_{i}^{P}, U_{j}^{P}\right)$. In a situation of war, they obtain the outside option $\left(\tilde{U}_{i}^{W}, \tilde{U}_{j}^{W}\right)$. Peace Pareto dominates war so that the gains of the winning country are lower than the losses of the defeated country:

$$
S^{P} \equiv U_{i}^{P}+U_{j}^{P}>\tilde{U}_{i}^{W}+\tilde{U}_{j}^{W} \equiv \tilde{S}^{W} .
$$

Escalation to war is avoided whenever countries $i$ and $j$ agree on a sharing rule of $S^{P}$. We assume that the outside options of each country $\left(\tilde{U}_{i}^{W}, \tilde{U}_{j}^{W}\right)$ are not perfectly known by the other country at the time of negotiation. More precisely:

$$
\tilde{U}_{i}^{W}=\left(1+\tilde{u}_{i}\right) U_{i}^{W}, \tilde{U}_{j}^{W}=\left(1+\tilde{u}_{j}\right) U_{j}^{W}, E\left(\tilde{u}_{i}\right)=E\left(\tilde{u}_{j}\right)=0, \operatorname{var}\left(\tilde{u}_{i}\right)=\operatorname{var}\left(\tilde{u}_{j}\right)=V^{2} / 8,
$$

where $\tilde{u}_{i}$ and $\tilde{u}_{j}$ are privately known by each country. Hence, the parameter $V$ measures the degree of informational asymmetry between the countries. On average, outside options are equal

4. Scholars in political sciences have developed two alternative arguments: (1) agents (and state leaders) may be irrational and misperceive the costs of war and (2) leaders may be those who enjoy the benefits of war while the costs are suffered by other agents (citizens and soldiers). We ignore those alternative explanations of war because it is unlikely that the trade openness channel interacts with them. Indeed, an irrational leader may decide to go to war whatever the trade loss suffered by his country. Similarly, the way the trade surplus (and the trade loss in case of conflict) is shared between political leaders and the rest of the population is not obvious. Hence, marginally, a larger level of trade openness has no clear-cut impact on the trade-off between the marginal benefits of war enjoyed by political leaders and the marginal costs suffered by the population. Consequently, internal politics do not play a role in our theoretical analysis. Studies on the relationship between domestic politics and war include Garfinkel (1994) and Hess and Orphanides (1995, 2001). An alternative model of conflict is offered by Yildiz (2004) in a multi-period bargaining model in which players are optimistic about their bargaining power but learn as they play the game. He shows that delay in bargaining (which can be interpreted as war) is possible in such a setup. In such a multi-period model, if war enables the winning country to appropriate the trade surplus (because it succeeds to impose more favourable terms of trade), the incentive of one country to attack might increase with trade. Finally, another model of war is offered by Alesina and Spolaore $(2005,2006)$ where wars occur because the country attacking has a first strike advantage. 


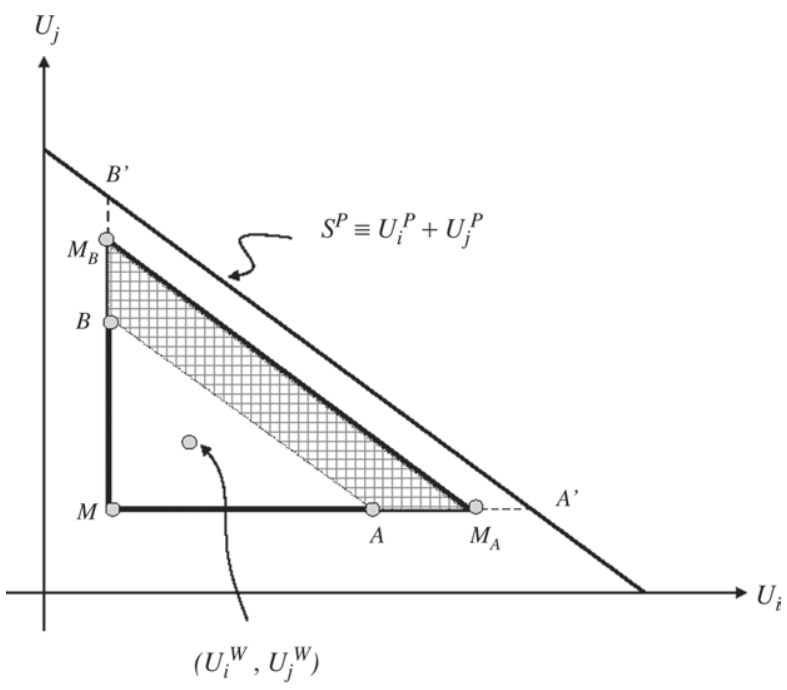

Average outside option

FIGURE 3

Negotiation under uncertainty

to the equilibrium values $\left(U_{i}^{W}, U_{j}^{W}\right)$ as determined in the next section. This formalization reflects the assumption that a country leader has better information on the force of its own military, the likely destructions in his own country, and the resilience of his citizens in the event of war. The important assumption in our setup is that a country leader has private information that helps him form more precise expectations on the fate of his own country in case of war than for the foreign country. Other sources of uncertainty could be added, but as long they are symmetric between the two countries, they would not alter our results.

Solving for the second best protocol in bargaining under private information constitutes one of the most celebrated results in the mechanism design literature (Myerson and Satherwaite, 1983). However, we cannot apply directly Myerson and Satherwaite's results because they assume that (1) once an agent has agreed to participate in the negotiation, it has no further right to quit the negotiation table and (2) private information should be independently distributed between agents. Hereafter, we relax both assumptions because we believe that they are not realistic in the context of interstate disputes that may escalate in wars. ${ }^{5}$ First, no institution (even the United Nations (UN)) has the power to forbid a sovereign country to leave negotiations and enter war. Hence, the class of protocols we consider, only those with no commitment mechanisms, is smaller than in Myerson and Satherwaite. Second, it is reasonable to think that in case of war, the disagreement payoffs are negatively correlated: losses for the winning country (in terms of territory, national honour, or freedom, for example) partially mirror gains for the other country.

The bargaining problem is depicted in Figure 3. Private information is partially correlated as $\left(\tilde{u}_{i}, \tilde{u}_{j}\right)$ are drawn in a uniform law distributed in the triangle $M M_{A} M_{B}$ where minimum and maximum values for $\left(\tilde{u}_{i}, \tilde{u}_{j}\right)$ are, respectively, $-V / 2$ and $+V$. Note that it is possible that

5. It is fundamental to relax simultaneously both assumptions. Relaxing the first one only would imply that war never occurs; indeed in the correlated case with interim participation constraints, Cremer and Mc Lean (1988) have shown that the first best efficiency can be obtained and players always reach an agreement. Compte and Jehiel (2005) show that relaxing assumption 2 in order to let agents quit negotiations at any time implies that private information, even if correlated, results in inefficiency, which in our context translates into possible escalation to war. 
even though peace Pareto dominates war, one country may be better off in the situation of war than in the situation of peace. This may be interpreted as a case where a war ends up with a winner. ${ }^{6}$ Following Compte and Jehiel (2005), we show in Appendix 1 that the bargaining protocol chosen optimally by the two countries corresponds to a Nash bargaining protocol. Importantly, with such a protocol, disagreements arise for every outside option $\left(\tilde{U}_{i}^{W}, \tilde{U}_{j}^{W}\right)$ inside the dashed area $A B M_{A} M_{B}$, where $A$ and $B$ are such that: $\overline{M A}=3 / 4 \overline{M A^{\prime}}$ and $\overline{M B}=3 / 4 \overline{M B^{\prime}}$. Intuitively, countries do not reach an agreement when the disagreement and agreement payoffs are sufficiently close. The reason is that during negotiations, countries do not report their true outside option. On the one hand, countries have an incentive to announce higher values of their outside option to extract a larger concession. On the other hand, they have an incentive to announce lower values in order to secure an agreement and avoid war. When the disagreement (war) and agreement (peace) payoffs are sufficiently close, the first effect dominates and countries escalate into war.

The probability of escalation to war corresponds to the surface of $A B M_{A} M_{B}$ divided by the surface of the triangle $M M_{A} M_{B}: \operatorname{Pr}\left(\right.$ escalation $\left._{i j}\right)=1-\frac{\overline{M A M B}}{\overline{M M_{A} M M_{B}}}$. Assuming that the informational noise $V$ is not too large, we obtain:

$$
\operatorname{Pr}\left(\text { escalation }_{i j}\right)=1-\frac{1}{4 V^{2}} \frac{\left[\left(U_{i}^{P}+U_{j}^{P}\right)-\left(U_{i}^{W}+U_{j}^{W}\right)\right]^{2}}{U_{i}^{W} U_{j}^{W}} .
$$

The probability of escalation to war increases with the degree of asymmetric information as measured here by the observational noise $V^{2}$ and decreases with the difference in the surplus under peace and under war, that is the total opportunity cost of war. ${ }^{7}$ Trade affects both surpluses as shown in the next section.

\subsection{Trade in a multi-country world}

Our theoretical framework is based on a standard new trade theory model with trade costs. The first reason we use such a model is that the multiplicity of trade partners is going to allow countries to diversify the origin of imports and therefore to decrease dependence on a single partner. This diversity effect is a natural feature of the Dixit-Stiglitz monopolistic competition model. Of course, the same results would apply if imperfectly substitutable intermediate goods were required to produce a final consumption good. The second reason is that distance between countries plays an important theoretical and empirical role for both trade and war and is relatively easy to manipulate in new trade models. Importantly, trade is economically beneficial to all countries in such a model.

The world consists of $R$ countries which produce differentiated goods under increasing returns. The utility of a representative agent in country $i$ is equal to consumption of a composite good $C$ made of all varieties produced in the world with the standard Dixit-Stiglitz form:

$$
U_{i}=C_{i}=\left[\sum_{h=1}^{R} n_{h} c_{i h}^{\frac{\sigma-1}{\sigma}}\right]^{\frac{\sigma}{\sigma-1}}
$$

6. Our setup includes such a possibility, but nothing constrains the war to end up with a clear loser or winner. This fits well with many military conflicts.

7. Note that we do not allow for spillovers so that the impact of the war between two countries on countries outside the country pair does not affect negotiations and the probability of escalation. In the model, conflicts outside the country pair do not affect the probability of escalation of the country pair. Even though we abstract from these spillovers in the theoretical model, we attempt to control for spatial spillovers in the empirical section. 
where $n_{h}$ is the number of varieties produced in country $h, c_{i h}$ is demand in country $i$ for a variety produced in country $h$, and $\sigma>1$ is the elasticity of substitution. Dual to this is the price index for each country:

$$
P_{i}=\left(\sum_{h=1}^{R} n_{h}\left(p_{h} T_{i h}\right)^{1-\sigma}\right)^{1 /(1-\sigma)},
$$

where $p_{h}$ is the mill price of products made in $h$ and $T_{i h}>1$ represents the iceberg trade costs often used in the trade literature. Those depend on distance and other trade impediments such as political borders or trade restrictions. If one unit of good is exported from country $h$ to country $i$, only $1 / T_{i h}$ units are consumed. In each country, the different varieties are produced under monopolistic competition and the entry cost requires $f$ units of a freely tradable good which is chosen as numeraire. Produced in perfect competition with labour only, this sector serves to fix the wage rate in country $i$ to its labour productivity $a_{i}$, common to both sectors so that the marginal cost of production is unity in all countries. This simplifies the analysis as this implies that wages are not affected by country size, market access, and trade costs. Mill prices in the manufacturing sector in all countries are identical and equal to the usual mark-up over marginal cost: $p_{i}=\sigma /(\sigma-1), \forall i$. As labour is the only factor of production, and agents are each endowed with 1 unit of labour, this implies that total expenditure of country $i$ is $E_{i}=\hat{L}_{i}$, where $\hat{L}_{i} \equiv a_{i} L_{i}$ is effective labour, productivity multiplied by $L_{i}$, the number of workers in country $i$. The number of firms is proportional to GDP and set equal to $n_{i}=\hat{L}_{i} /(f \sigma)$. The value of imports by country $i$ from country $j$ then depends on both countries' incomes, prices, and trade costs:

$$
m_{i j} \equiv n_{j} p_{j} T_{i j} c_{i j}=E_{i} E_{j}\left(\frac{p_{j} T_{i j}}{P_{i}}\right)^{1-\sigma},
$$

a standard gravity equation. At equilibrium, utility increases with trade flows and the number of varieties and decreases with trade costs:

$$
U_{i}=\frac{\sigma-1}{\sigma}\left(\frac{f}{\sigma}\right)^{\frac{-1}{\sigma-1}}\left[\sum_{h=1}^{R} n_{h}^{\frac{1}{\sigma}}\left(\frac{m_{i h}}{T_{i h}}\right)^{\frac{\sigma-1}{\sigma}}\right]^{\frac{\sigma}{\sigma-1}} .
$$

We assume that the possible economic effects of a war between country $i$ and country $j$ are (1) a decrease of $\lambda \%$ in effective labour $\hat{L}_{i}$ and $\hat{L}_{j}$ in both countries (which may come from a loss in productivity or/and in factors of production); and (2) an increase of $\tau_{\text {bil }} \%$ and $\tau_{\text {multi }} \%$, in, respectively, the bilateral and the multilateral trade costs $T_{i j}$ and $T_{i h}, h \neq i, j$, on differentiated goods. During conflicts, borders are closed, transport infrastructures are destroyed, and confidence is shaken. These can affect both bilateral and multilateral trade costs. Note that the assumed percentage increase in trade costs due to war is the same across the two fighting countries, but that the level of initial trade costs between countries differs across country pairs.

To sum up, a country $i$ 's welfare under peace is $U_{i}^{P}=U\left(x_{i}\right)$, where the vector $x_{i} \equiv$ $\left(\hat{L}_{i}, \hat{L}_{j}, T_{i j}, T_{i h}\right)$. Under war, country $i$ 's welfare is stochastic (see equation (2)) but is equal on average to an equilibrium value $U_{i}^{W}=U\left[x_{i}(1-\Delta)\right]$ with: $\Delta \equiv\left(\lambda, \lambda,-\tau_{\text {bil }},-\tau_{\text {multi }}\right)$.

\subsection{Trade openness and war}

According to our model, the probability of escalation to war between country $i$ and country $j$ is given by equation (3). Together with equation (7), we show in Appendix 2 that, using a Taylor expansion around the symmetric equilibrium where countries $i$ and $j$ are identical in size, war occurs with probability:

$$
\operatorname{Pr}\left(\text { escalation }_{i j}\right)=1-\frac{1}{V^{2}}\left[W_{1} \lambda+W_{2} \tau_{\text {bil }}+W_{3} \tau_{\text {multi }}\right]^{2} .
$$


The term in brackets is the total welfare differential between war and peace for both countries. This differential has three components, which are given in Appendix 2. The first one, $W_{1}>0$, says that war reduces available resources among belligerents. The negative impact on welfare comes from the direct impact on wages and income and from the indirect impact on the number of varieties consumed (locally produced and imported from $j$ ). The second component, $W_{2}>0$, stands for the fact that war potentially increases bilateral trade costs and consumer prices and therefore decreases bilateral trade. Similarly, the third component, $W_{3}>0$, stands for the possible increase of multilateral trade costs, which also generate higher consumer prices.

Importantly, equation (8) can also be rewritten in terms of the observable trade patterns. For this, we use equation (6) and the national accounting identity: $\frac{m_{i i}}{E_{i}}+\frac{m_{i j}}{E_{i}}+\sum_{h \neq j, i}^{R} \frac{m_{i h}}{E_{i}}=1$, where $m_{i i}$ is the value of trade internal to country $i$ and $\left(m_{i j}, m_{i h}\right)$ are the observable trade flows in final goods. We then obtain the probability of escalation as a function of observable bilateral import flows $\left(\frac{m_{i j}}{E_{i}}\right)$ and multilateral import flows $\left(\sum_{h \neq j, i}^{R} \frac{m_{i h}}{E_{i}}\right)$ as ratios of income:

$$
\operatorname{Pr}\left(\text { escalation }_{i j}\right)=1-\frac{1}{V^{2}}\left\{\frac{\sigma \lambda}{\sigma-1}+\tau_{\mathrm{bil}} \frac{m_{i j}}{E_{i}}-\left(\frac{\lambda}{\sigma-1}-\tau_{\text {multi }}\right) \sum_{h \neq j, i}^{R} \frac{m_{i h}}{E_{i}}\right\}^{2} .
$$

This is the key equation of our model which brings two important implications that are tested in the empirical section.

Testable implication 1. An increase in bilateral imports of $i$ from $j$, as a ratio of country $i$ 's income, decreases the probability of escalation to war between these two countries.

This prediction holds under the condition that $\tau_{\text {bil }}>0$ : bilateral trade costs increase following a war between $i$ and $j .{ }^{8}$ We test this condition in the empirical section and find that it holds. If war increases bilateral trade costs, it lowers trade gains the more so, the higher the ex ante import flows. Hence, observed bilateral trade openness reveals one opportunity cost of a bilateral war.

Testable implication 2. An increase in multilateral imports (from countries other than $j$ ), as a ratio of country $i$ 's income, implies a higher probability of escalation to war between countries $i$ and $j$.

This prediction holds under a stricter condition than the one necessary for Testable implication 1, namely that: $\tau_{\text {multi }}<\frac{\lambda}{\sigma-1}$, the increase in multilateral trade costs following a war with $j$ is small enough compared to the welfare loss due to the decrease in the number of varieties consumed that comes from the loss in factors of production of $i$ and $j$. In the empirical section, we find that the impact of military conflicts on multilateral trade costs is indeed either small or insignificant in the post-World War II period. In addition, empirical work by Hess (2004) shows that economic costs of conflicts are large, which in the context of our model suggests that $\lambda$, the percentage decrease in effective labour and income, is statistically large. The intuition for Testable implication 2 is that a high level of multilateral trade reduces the opportunity cost of a conflict with $j$ : The welfare loss due to the fall in varieties from $i$ and $j$ is lower when internal trade flows and import flows from $j$ are smaller in proportion of total expenditures, that is, when multilateral trade openness is large. When $\tau_{\text {multi }}<\frac{\lambda}{\sigma-1}$, observed multilateral openness effectively reduces the opportunity cost of a bilateral war and the incentive to make concessions in order to avoid escalation to war. The reason for the possible theoretical ambiguity is that if a bilateral war increases multilateral trade costs to a large extent, then the opportunity cost of a war increases with observed multilateral trade openness. Note also that a high elasticity of substitution between varieties $(\sigma)$ reduces the insurance effect that multilateral trade provides in case of war. The reason

8. The term in the curly brackets in equation (9) is positive because the import-to-income ratio is lower than $\sigma>1$. 
is that in the Dixit-Stiglitz framework, a high elasticity of substitution lowers welfare gains from diversity. The results for the complements' case ${ }^{9}$ may differ substantially because multilateral trade flows would not act as a potential substitute to bilateral flows in this case and (e.g. in the case of intermediate goods) may actually reverse the impact of multilateral trade on the risk of war. The case of imperfect substitutability is, however, broadly consistent with the evidence on the elasticity of substitution between domestically and foreign produced goods in the empirical trade literature, which routinely produces estimates of those elasticities centred around $8 .{ }^{10}$

We now discuss the impact of globalization on war. By differentiating equation (8), we obtain the effect on the probability of escalation of a decrease in bilateral trade barriers $T_{i j}$. Appendix 2 shows that lower bilateral trade costs between $i$ and $j$ decrease the probability of escalation to war between these two countries: $\frac{\left.d \operatorname{Pr}^{2} \text { escalation }_{i j}\right)}{d\left(-T_{i j}\right)}<0$. A sufficient condition for this result to hold is $\tau_{\text {multi }}<\frac{\lambda}{\sigma-1}$. The intuition is similar to Testable implication 1. Under the same condition, a decrease in trade costs of country $i$ with other countries than country $j$ implies a higher probability of escalation to war with country $j: \frac{d \operatorname{Pr}\left(\text { escalation }_{i j}\right)}{d\left(-T_{i h}\right)}>0$.

A direct consequence of these two results is that regional and multilateral trade liberalization may have very different implications for the prevalence of war. Regional trade agreements between a group of countries will unambiguously lead to lower prevalence of regional conflicts but may increase conflicts with other regions. To the opposite, multilateral trade liberalization may increase the prevalence of bilateral conflicts.

We can use our model to shed light on the following question: Why has the process of globalization not led to a decrease in the number of military conflicts as was hoped in the beginning of the 1990's? For simplicity, we assume that the world is made of $R$ identical countries with symmetric trade barriers, $T_{i j}=T$ for all $i, j$. We interpret globalization as a uniform decrease in trade barriers between all country pairs.

Result 1. Globalization-interpreted as a symmetric decrease in trade costs-increases the probability of war between all country pairs (see Appendix 2 for proof):

$$
\frac{d \operatorname{Pr}\left(\text { escalation }_{i j}\right)}{d(-T)}>0 \text { if }\left[\frac{\lambda}{\sigma-1}-\tau_{\text {multi }}\right](R-2)>\tau_{\text {bil }} .
$$

This result holds when the increase in multilateral trade costs $\left(\tau_{\text {multi }}\right)$ following a bilateral conflict is low and when the number of countries $(R)$ is sufficiently large. The reason is that in a world where countries have a very diverse set of trade partners, globalization reduces the bilateral economic dependence and the opportunity cost of war for all country pairs. The intuition that trade is good for peace can actually be reversed. There is an important proviso to this (pessimistic) message. Multilateral trade liberalization changes the nature of war: It increases the probability of small-scale wars, but it decreases the probability of a large-scale war. $R$ is the number of countries in the model but can also be interpreted as the number of coalitions with a dispute that may or may not escalate into a war. In the limit, when $R=2$, globalization unambiguously decreases the probability of a World War between two coalitions of countries for the same reason that bilateral trade liberalization induces a lower probability of bilateral war. If one thinks that World Wars are the most costly in terms of human welfare, then globalization plays a very positive role.

An interesting implication of Result 1 is that it is consistent with graph 2, which suggests that since World War II, military conflicts have become more local. The probability of a military conflict between two countries is the probability of a dispute between countries $i$ and $j$ multiplied

9. The case of complements cannot be analysed in our framework of monopolistic competition, which requires an elasticity of substitution between varieties larger than 1 .

10. Using three-digit U.S.-Canada trade and tariff data, Head and Ries (2001) obtain a benchmark estimate of $\sigma=$ 7.9. With a different methodology, Broda and Weinstein (2006) obtain average estimates of the elasticity of substitution between 4 and 12.6 for U.S. imports over the 1990-2001 period (table IV). 
by the conditional probability of escalation:

$$
\operatorname{Pr}\left(\text { conflict }_{i j}\right)=\operatorname{Pr}\left(\text { dispute }_{i j}\right) \times \operatorname{Pr}\left(\text { escalation }_{i j} \mid \text { dispute }_{i j}\right) .
$$

Result 1 implies that the probability of escalation is affected positively by globalization. The probability of a dispute (which we assume to be independent of globalization) is higher for proximate countries, a stylized fact well known in political science and that we confirm in the empirical section. Hence, globalization increases the probability of a military conflict especially for country pairs with a high probability of dispute, which are typically proximate country pairs. ${ }^{11}$

\section{EMPIRICAL ANALYSIS}

\subsection{Data description on conflicts}

Most of the data we use in this paper come from the COW project that makes available (at http://cow2.la.psu.edu/) a very large array of data sets related to armed conflicts over the last century. Our principal dependent variable is the occurrence of an MID between two countries. This data set is available for the years 1816-2001, but we only use the years 1950-2000 because this is the period for which our principal explanatory variables, bilateral and multilateral trade over income ratios, are available on a large scale. Each MID is coded with a hostility level ranging from 1 to 5 ( 1 = No militarized action, $2=$ Threat to use force, $3=$ Display of force, $4=$ Use of force, and $5=$ War). ${ }^{12}$ In the COW project, war is defined as a conflict with at least 1000 deaths of military personnel. By this standard, fewer than 100 interstate wars have been fought since 1815. At the country pair level of analysis, the number of pairs of states at war is naturally larger, since in multi-state wars, each state on one side would be paired with every state on the other. Even so, the small number of warring country pairs inhibits the creation of truly robust estimates of war determinants. Consequently, it is common in the empirical literature to analyse the causes of MIDs using a broader definition: display of force, use of force, and war itself. Table A1 in Appendix C describes specific examples of MIDs. Examples of display of force (level 3 of an MID) include a decision of mobilization, a troop or ship movement, a border violation, or a border fortification. These are government-approved and unaccidental decisions. Examples of use of force (level 4 of an MID) include a blockade, an occupation of territory, or an attack. ${ }^{13}$ In the rest of this paper, we thus consider MID $_{i j t}$ to be equal to 1 (and 0 otherwise) if an MID of hostility level 3, 4, or 5 occurs at date $t$ between countries $i$ and $j$. We have also investigated with a hostility level of MID restricted to 4 and 5 and find qualitatively similar results (see robustness check regressions in Tables 4 and 5). Our sample consists, for each year of the 1950-2000 period, of all country pair combinations ("dyads") in existence. Of this universe of dyads, few are in fact engaged in an MID, even with our enlarged definition. As appears in Table 1, our universe sample contains 536,381 observations, of which $2390(0.45 \%)$ are engaged in a military conflict according to our definition. In our preferred specification below (column 4 of Table 3) - where we lose a substantial number of observations due to missing values in the explanatory variables - this overall war frequency is approximately preserved (1223 conflicts of 223,788 dyads, i.e. 0.55\%). The rest of the data sources are described in Appendix 4.

11. To prove this, differentiate equation (10) with respect to $T$. If, due to globalization, $T$ decreases over time, and the probability of dispute is itself a decreasing function of distance, then, using Result 1 , the probability of conflict between proximate countries increases with time relative to the one between distant countries. project.

12. More detail about these data is available in Jones et al. (1996), Faten et al. (2004), and online on the COW

13. We drop the incidents that consist of boat seizures. Political scientists often recommend dropping those incidents, since they mostly concern conflicts related to fishing areas, which are difficult to compare with the other armed conflicts in our sample. Those boat seizures are relatively infrequent and leaves our main results unaffected. 
TABLE 1

Distribution of conflicts' intensity over 1950-2000

\begin{tabular}{lcccccc}
\hline & \multicolumn{2}{c}{ Full sample } & & \multicolumn{2}{c}{ Restricted sample } \\
\cline { 2 - 3 } \cline { 5 - 6 } Non-fighting dyads & \multicolumn{2}{c}{533,991} & & & 222,565 \\
\hline Hostility level of militarized interstate dispute & Frequency & $\%$ & & Frequency & $\%$ \\
\hline 3 (Display of force) & 455 & $19 \cdot 04$ & & 280 & $22 \cdot 89$ \\
4 (Use of force) & 1,482 & $62 \cdot 01$ & & 809 & $66 \cdot 15$ \\
5 (War) & 453 & $18 \cdot 95$ & & 134 & $10 \cdot 96$ \\
Total & 2,390 & 100 & & 1,223 & 100 \\
\hline
\end{tabular}

Note: The restricted sample is from our preferred specification in the first set of regressions (column 4 of Table 3).

\subsection{The effect of military conflicts on trade barriers}

The first step of our empirical analysis is to assess the impact of past military conflicts on both bilateral and multilateral trade patterns. The aim of this section is to test the conditions that bilateral trade barriers increase after a bilateral conflict and that a bilateral conflict has a small effect on multilateral trade barriers (these are the conditions that enable us to sign the theoretical impact of trade on the probability of escalation to a military conflict in equation (9)). We therefore want to evaluate empirically $\tau_{\text {bil }}$ and $\tau_{\text {multi }}$, the impact of a military conflict on the levels of bilateral and multilateral trade barriers.

To do this, note that using equation (6), reintroducing time subscripts, and neglecting constants, we obtain that bilateral imports at time $t$ of country $i$ from country $j$ are an increasing function of income in the importing country $E_{i t}$, income in the exporting country $E_{j t}$, bilateral trade freeness $T_{i j t}^{1-\sigma}$ (since $\sigma>1$ ), and a price index $P_{i t}$ specific to the importing country. While the rest of equation (6) is relatively straightforward to estimate, this last term is hard to measure empirically but important theoretically. Anderson and van Wincoop (2004) highlight the biases that can arise when omitting this term and the various solutions to the estimation problem raised by it. The simplest solution here is to use a convenient feature of the CES demand structure that makes relative imports from a given exporter independent of the characteristics of third countries. We can eliminate price indexes in the bilateral trade equation by choosing the imports from the U.S. as a benchmark of comparison for all imports of each importing country:

$$
\frac{m_{i j t}}{m_{i u t}}=\frac{E_{j t}}{E_{u t}}\left(\frac{T_{i j t}}{T_{i u t}}\right)^{1-\sigma},
$$

where the first term of relative productivity-adjusted labour forces is proportional to relative output and the second term involves trade costs of imports of country $i$ from country $j$ relative to the U.S. $(u)$. Since the price index of the importer does not depend on the characteristics of the exporter, it cancels out here, which solves the mentioned issue in estimation. The last step is to specify the trade costs function. Here, we follow the gravity literature in the list of trade costs components (see Rose, 2004, for recent worldwide gravity equations comparable to our work in terms of time and country coverage). We separate trade costs between non-policy-related variables (bilateral distance, contiguity, similarity in languages, and colonial links), policy-related ones (trade agreements and a communist regime dummy), and those induced by militarized conflicts, as measured by the vector MID $_{i j}$ :

$$
\begin{aligned}
T_{i j t}= & d_{i j}^{\delta_{1}} \exp \left(\delta_{2} \text { cont }_{i j}+\delta_{3} \operatorname{lang}_{i j}+\rho_{1} \operatorname{col}_{i j}+\rho_{2} \operatorname{ccol}_{i j}\right. \\
& \left.+\rho_{3} \mathrm{rta}_{i j t}+\rho_{4} \text { gatt }_{i j t}+\rho_{5} \operatorname{com}_{i j t}+\rho_{6} \mathbf{M I D}_{i j}\right),
\end{aligned}
$$


where $d_{i j}$ is bilateral distance and $\operatorname{cont}_{i j}, \operatorname{col}_{i j}, \mathrm{ccol}_{i j}$, and $\mathrm{com}_{i j t}$ are dummy variables indicating, respectively, whether the two countries have a common border, whether one was a colony of the other at some point in time, whether the two have been colonized by a same third country, and whether one is a communist regime. We also account for common membership in a regional trade area, the $\mathrm{rta}_{i j t}$ dummy. A variable counting the number of General Agreement on Tariffs and Trade/World Trade Organization (GATT/WTO) members in the country pair is also included. All those variables have been shown in the empirical trade literature to be significant predictors of trade flows. The elements of the vector $\mathbf{M I D}_{i j}$ are the yearly lags and leads of dummies, indicating the occurrence of an MID. Their exact nature is made clearer below. Combining equation (12) with equation (11), our variable of interest, the $\mathbf{M I D}_{i j}$ vector of dummies, therefore has an effect on trade costs which can be estimated by the following equation:

$$
\begin{aligned}
& \ln \left(\frac{m_{i j t}}{m_{i u t}}\right)=\ln \left(\frac{\mathrm{GDP}_{j t}}{\mathrm{GDP}_{u t}}\right)+(1-\sigma)\left[\delta_{1} \ln \left(\frac{d_{i j t}}{d_{i u t}}\right)+\delta_{2}\left(\Delta_{\mathrm{us}} \operatorname{cont}_{i j}\right)+\delta_{3}\left(\Delta_{\mathrm{us}} \operatorname{lang}_{i j}\right)\right] \\
& +(1-\sigma)\left[\rho_{1}\left(\Delta_{\mathrm{us}} \operatorname{col}_{i j}\right)+\rho_{2}\left(\Delta_{\mathrm{us}} \operatorname{ccol}_{i j}\right)+\rho_{3}\left(\Delta_{\mathrm{us}} \mathrm{rta}_{i j}\right)\right. \\
& \left.+\rho_{4}\left(\Delta_{\mathrm{us}} \text { gatt }_{i j}\right)+\rho_{5} \operatorname{com}_{i j t}\right]+(1-\sigma) \rho_{\mathbf{6}}\left(\Delta_{\mathrm{us}} \mathbf{M I D}_{i j}\right),
\end{aligned}
$$

where the short cut $\Delta_{\text {us }}$ designates the fact that all variables are in difference with respect to the U.S. so that for instance, $\Delta_{\mathrm{us}} \operatorname{lang}_{i j}=\left(\operatorname{lang}_{i j}-\operatorname{lang}_{i u}\right)$.

3.2.1. Results. We estimate the impact of military conflict on trade both through a traditional gravity equation, which neglects the price index issue (results are in the first two columns of Table 2), and with equation (13) that takes into account this concern by considering all variables (including the conflict variable) relative to the U.S. (results are in the last two columns of Table 2). All regressions include year dummies (not shown in the regression tables). All estimates other than the conflict variables, in both sets of results, are reasonably similar to what is usually found in the literature. ${ }^{14}$

We allow for the possibility that a military conflict can have contemporaneous as well as delayed effects on bilateral trade barriers (up to 20 years): In the vector $\mathbf{M I D}_{i j}$, this corresponds to variables bil. MID $_{i j t}-$ bil. MID $_{i j t+20}$. Whether in the traditional gravity equation (column 1) or in the difference with the U.S. version (column 3), the impact of a bilateral military conflict has a sizeable impact on bilateral trade. During a military conflict, trade falls by $\exp (-0 \cdot 244)-1 \simeq$ $22 \%$ relative to the gravity prediction; this effect remains of the same order in the three following years. When all variables are in difference to the U.S., the impact is larger: The contemporary fall is about $38 \%$ in column (3). We also find that the fall is long lasting as the conflict coefficient is significant and negative for at least 10 years. These results are in between those found by Morrow et al. (1998) and Blomberg and Hess (2006) on the one hand and by Glick and Taylor (2005) on the other hand. The former papers find no statistical significance in the negative effect of military disputes on bilateral trade in their different specifications (a very reduced-form gravity equation for Morrow et al., 1998, and a more theory-based one for Blomberg and Hess, 2006). Glick and Taylor (2005) find a much larger contemporaneous effect in a sample that includes the two World

14. We have checked that the inclusion of the control GDP per capita variable, often introduced in the gravity literature, but which does not come naturally in our theoretical setup, does not change our results. 
TABLE 2

Impact of militarized interstate dispute on trade

\begin{tabular}{|c|c|c|c|c|}
\hline & \multicolumn{4}{|c|}{ Dependent variables } \\
\hline & \multicolumn{2}{|c|}{ ln imports } & \multicolumn{2}{|c|}{$\ln m_{i j t} / m_{\text {iut }}$} \\
\hline & Model (1) & Model (2) & Model (3) & Model (4) \\
\hline $\ln$ GDP origin & $\begin{array}{l}0.959^{* * * *} \\
(0 \cdot 006)\end{array}$ & $\begin{array}{c}0.940 * * * \\
(0 \cdot 007)\end{array}$ & $\begin{array}{c}1 \cdot 001 * * * \\
(0 \cdot 007)\end{array}$ & $\begin{array}{l}0 \cdot 976 * * * \\
(0 \cdot 008)\end{array}$ \\
\hline ln GDP destination & $\begin{array}{c}0 \cdot 847 * * * \\
(0 \cdot 006)\end{array}$ & $\begin{array}{l}0.846^{* * * *} \\
(0 \cdot 007)\end{array}$ & - & - \\
\hline ln distance & $\begin{array}{l}-1.008^{* * * *} \\
(0.017)\end{array}$ & $\begin{array}{c}-0.991 * * * \\
(0 \cdot 019)\end{array}$ & $\begin{array}{c}-1 \cdot 188^{* * *} \\
(0 \cdot 018)\end{array}$ & $\begin{array}{l}-1 \cdot 158 * * * \\
(0 \cdot 019)\end{array}$ \\
\hline Contiguity & $\begin{array}{c}0.452 * * * \\
(0.075)\end{array}$ & $\begin{array}{c}0.412 * * * \\
(0 \cdot 078)\end{array}$ & $\begin{array}{c}0 \cdot 663 * * * \\
(0.066)\end{array}$ & $\begin{array}{c}0 \cdot 680 * * * \\
(0 \cdot 069)\end{array}$ \\
\hline Similarity in language index & $\begin{array}{c}0 \cdot 331^{* * * *} \\
(0 \cdot 070)\end{array}$ & $\begin{array}{l}0.301 * * * \\
(0 \cdot 074)\end{array}$ & $\begin{array}{l}0 \cdot 128^{* *} \\
(0 \cdot 062)\end{array}$ & $\begin{array}{l}0.112 * \\
(0.065)\end{array}$ \\
\hline Colonial link ever & $\begin{array}{l}1 \cdot 121^{* * * *} \\
(0 \cdot 088)\end{array}$ & $\begin{array}{c}1.060 * * * \\
(0 \cdot 093)\end{array}$ & $\begin{array}{l}0.302 * * * \\
(0 \cdot 061)\end{array}$ & $\begin{array}{c}0 \cdot 257 * * * \\
(0 \cdot 063)\end{array}$ \\
\hline Common colonizer post-1945 & $\begin{array}{c}0 \cdot 568 * * * \\
(0 \cdot 058)\end{array}$ & $\begin{array}{l}0.499 * * * \\
(0.064)\end{array}$ & $\begin{array}{l}0.545^{* * * *} \\
(0.063)\end{array}$ & $\begin{array}{c}0 \cdot 450 * * * \\
(0 \cdot 069)\end{array}$ \\
\hline Preferential trade arrangement & $\begin{array}{c}0 \cdot 545^{* * * *} \\
(0 \cdot 049)\end{array}$ & $\begin{array}{c}0.539 * * * \\
(0 \cdot 052)\end{array}$ & $\begin{array}{c}0.441 * * * \\
(0 \cdot 049)\end{array}$ & $\begin{array}{c}0.426 * * * \\
(0.053)\end{array}$ \\
\hline Number of GATT/WTO members & $\begin{array}{c}0 \cdot 204 * * * \\
(0 \cdot 021)\end{array}$ & $\begin{array}{c}0.223 * * * \\
(0 \cdot 022)\end{array}$ & $\begin{array}{c}0.337 * * * \\
(0.034)\end{array}$ & $\begin{array}{c}0 \cdot 364 * * * \\
(0.036)\end{array}$ \\
\hline One communist regime among partners & $\begin{array}{c}-0.399 * * * \\
(0.032)\end{array}$ & $\begin{array}{c}-0.422 * * * \\
(0.034)\end{array}$ & $\begin{array}{c}-0.720 * * * \\
(0.045)\end{array}$ & $\begin{array}{c}-0 \cdot 767 * * * \\
(0.045)\end{array}$ \\
\hline bil. MID + 0 years & $\begin{array}{c}-0.245^{* * *} \\
(0.059)\end{array}$ & $\begin{array}{c}-0 \cdot 244 * * * \\
(0 \cdot 044)\end{array}$ & $\begin{array}{c}-0.485 * * * \\
(0.036)\end{array}$ & $\begin{array}{c}-0.434 * * * \\
(0.032)\end{array}$ \\
\hline bil. MID + 1 years & $\begin{array}{c}-0.213^{* * *} * \\
(0.047)\end{array}$ & $\begin{array}{c}-0.238 * * * \\
(0 \cdot 047)\end{array}$ & $\begin{array}{c}-0.417 * * * \\
(0 \cdot 026)\end{array}$ & $\begin{array}{c}-0 \cdot 340 * * * \\
(0.028)\end{array}$ \\
\hline bil. MID + 2 years & $\begin{array}{c}-0 \cdot 224 * * * \\
(0 \cdot 040)\end{array}$ & $\begin{array}{c}-0.199 * * * \\
(0 \cdot 040)\end{array}$ & $\begin{array}{c}-0 \cdot 373 * * * \\
(0 \cdot 028)\end{array}$ & $\begin{array}{c}-0.287 * * * \\
(0.030)\end{array}$ \\
\hline bil. MID + 3 years & $\begin{array}{c}-0.245 * * * \\
(0.038)\end{array}$ & $\begin{array}{c}-0.229 * * * \\
(0.038)\end{array}$ & $\begin{array}{c}-0.495 * * * \\
(0.026)\end{array}$ & $\begin{array}{c}-0.472 * * * \\
(0.029)\end{array}$ \\
\hline bil. MID + 4 years & $\begin{array}{c}-0.162 * * * \\
(0.041)\end{array}$ & $\begin{array}{c}-0.139 * * * \\
(0 \cdot 045)\end{array}$ & $\begin{array}{c}-0.329 * * * \\
(0 \cdot 026)\end{array}$ & $\begin{array}{c}-0.327 * * * \\
(0.028)\end{array}$ \\
\hline bil. MID + 5 years & $\begin{array}{l}-0.021 \\
(0.034)\end{array}$ & $\begin{array}{c}0.001 \\
(0.036)\end{array}$ & $\begin{array}{c}-0 \cdot 196 * * * \\
(0 \cdot 030)\end{array}$ & $\begin{array}{c}-0.323 * * * \\
(0.034)\end{array}$ \\
\hline bil. MID + 6 years & $\begin{array}{l}-0.047 \\
(0.031)\end{array}$ & $\begin{array}{l}-0.018 \\
(0.030)\end{array}$ & $\begin{array}{c}-0 \cdot 156 * * * \\
(0 \cdot 022)\end{array}$ & $\begin{array}{c}-0.097 * * * \\
(0.027)\end{array}$ \\
\hline bil. MID + 7 years & $\begin{array}{l}-0.024 \\
(0.029)\end{array}$ & $\begin{array}{l}-0.022 \\
(0.032)\end{array}$ & $\begin{array}{c}-0 \cdot 193 * * * \\
(0 \cdot 026)\end{array}$ & $\begin{array}{c}-0.138 * * * \\
(0.026)\end{array}$ \\
\hline bil. MID + 8 years & $\begin{array}{l}-0.051 * * \\
(0.025)\end{array}$ & $\begin{array}{l}-0.067 * * \\
(0.029)\end{array}$ & $\begin{array}{c}-0 \cdot 108 * * * \\
(0 \cdot 026)\end{array}$ & $\begin{array}{c}-0.118 * * * \\
(0.029)\end{array}$ \\
\hline bil. MID + 9 years & $\begin{array}{l}-0.023 \\
(0.028)\end{array}$ & $\begin{array}{l}-0.024 \\
(0.029)\end{array}$ & $\begin{array}{c}-0 \cdot 082 * * * \\
(0.023)\end{array}$ & $\begin{array}{c}-0.046 * * \\
(0.023)\end{array}$ \\
\hline bil. MID + 10 years & $\begin{array}{l}-0.045 * \\
(0.023)\end{array}$ & $\begin{array}{c}-0.060 * * \\
(0.027)\end{array}$ & $\begin{array}{c}-0 \cdot 164 * * * \\
(0.023)\end{array}$ & $\begin{array}{c}-0.133 * * * \\
\quad(0.026)\end{array}$ \\
\hline bil. MID + 11 years & $\begin{array}{l}-0.014 \\
(0.026)\end{array}$ & $\begin{array}{l}-0.025 \\
(0.029)\end{array}$ & $\begin{aligned}-0.077 * * * \\
\\
(0.022)\end{aligned}$ & $\begin{array}{c}-0.077 * * * \\
(0.024)\end{array}$ \\
\hline bil. MID - 1 years & & $\begin{array}{l}-0.086 * * \\
(0.041)\end{array}$ & & $\begin{array}{c}-0.285 * * * \\
(0.030)\end{array}$ \\
\hline bil. MID - 2 years & & $\begin{array}{l}-0.009 \\
(0.042)\end{array}$ & & $\begin{array}{c}-0.214 * * * \\
(0.028)\end{array}$ \\
\hline bil. MID - 3 years & & $\begin{array}{c}0 \cdot 011 \\
(0 \cdot 044)\end{array}$ & & $\begin{array}{c}-0.126 * * * \\
(0.026)\end{array}$ \\
\hline bil. MID - 4 years & & $\begin{array}{l}-0.033 \\
(0.047)\end{array}$ & & $\begin{array}{l}-0.003 \\
(0.024)\end{array}$ \\
\hline bil. MID - 5 years & & $\begin{array}{l}-0.094 \\
(0 \cdot 059)\end{array}$ & & $\begin{array}{c}-0.105 * * * \\
\quad(0.033)\end{array}$ \\
\hline$N$ & 300323 & 244440 & 286179 & 231519 \\
\hline$R^{2}$ & 0.633 & $0 \cdot 622$ & $0 \cdot 571$ & $0 \cdot 556$ \\
\hline RMSE & $1 \cdot 862$ & $1 \cdot 845$ & $2 \cdot 042$ & $2 \cdot 016$ \\
\hline
\end{tabular}

Notes: Columns (1) and (2): simple gravity estimates. Columns (3) and (4): all variables relative to the U.S. S.E. in parentheses with $* * *, * *$, and $*$, respectively, denoting significance at the $1 \%, 5 \%$, and $10 \%$ levels. Robust S.E. clustered by dyad. 
Wars and only the highest hostility levels for MIDs. ${ }^{15}$ Anderton and Carter (2001) also find a negative impact of wars on trade for several pairs of countries.

In columns (2) and (4) of Table 2, we investigate whether trade flows "anticipate" a conflict. We add dummies for the 5 years preceding the conflict. If those are also negative and significant, it will point to a common cause that structurally explains why a specific country pair both trades less than the gravity norm and experiences armed conflicts. In addition, if the coefficient values increase (in absolute value) as we get closer to the conflict, it might suggest, for example, that business climate deteriorates between the belligerent countries before the conflict itself. In the traditional gravity equation, no significant effect can be detected. In the version relative to the U.S., the dummies for the 3 years preceding the conflict are negative and significant. We have experimented with the use of Switzerland as an alternative to the U.S. as the reference country. Whereas other results were similar, the impact of conflict on past trade was insignificant. To summarize, and after having experienced with many different time windows both backward and forward, whereas the evidence that trade is affected by the expectation of conflict is mixed, a military conflict has a large and persistent effect on future trade. The effect lasts between 10 and 20 years.

We also want to investigate the impact of conflicts on total (multilateral) trade. This is done by inserting in the bilateral trade equation dummies set to 1 when the exporter or the importer is in conflict with another country than the trade partner. It therefore also gives the impact of conflicts on overall exports and imports with countries not in the conflict. This regression thus involves 75 dummies (on top of the year dummies and of the other variables from equation 13): 25 for the bilateral impact and 50 for the multilateral effects ( 25 for exports and 25 for imports). ${ }^{16}$ This regression yields our preferred estimates as it accounts for the full set of potential bilateral and multilateral impacts of a conflict over a long period of time ( 5 years pre-conflict and 20 years post-conflict) and deals properly with the price index issue.

Admittedly, the table is difficult to read, and we prefer to represent estimates of interest graphically, using three different "event-type" figures. Figure 4 shows, using this regression, the fall of bilateral trade relative to "natural" trade with 5\% confidence intervals in grey bands. There is a significant effect of an upcoming conflict on bilateral trade for the 3 years preceding it. The effect of a military conflict on contemporaneous trade is large: The coefficient implies a more than $35 \%$ decrease in trade from its natural level. It then decreases in absolute value, and the fighting country pair recovers a level of trade not statistically different from the norm around the 17 th year after the conflict.

In Figure 5, using the same regression, the impacts on multilateral exports and imports are depicted, respectively. The effect is either not statistically significant, for exports, or negative but very small, for imports (around 5\% when significant). Overall, these empirical results confirm the validity of the conditions necessary to sign Testable implications 1 and 2 derived in the theoretical section.

\subsection{The impact of trade on MIDs}

3.3.1. Empirical strategies. In this section, we test our central theoretical predictions related to the impact of trade openness on conflicts. Allowing for asymmetry between countries

15. In Glick and Taylor (2005), the treatment of repeated MIDs also tends to increase the contemporaneous effect. They only consider the latest MID to be relevant in their set of lagged variables. For instance, if a conflict occurs in year $t$ but another one happened in year $t-3$, the dummy bil. $\operatorname{MID}_{i j-3}=0$ in their case, while it is kept equal to 1 in ours. The method used in Glick and Taylor (2005) will tend to increase the impact of contemporaneous conflicts, since the low level of trade in year $t$ is partly due to the past conflicts which are not controlled for.

16. This is a simple linear regression with S.E. clustered by dyad. We experimented with a Heckman selection model to take into account the possibility that zero trade flows in conflict years might affect our estimates (the first stage being a probit with standard gravity controls and time dummies explaining whether the trade flow is zero or positive). The impacts of MIDs on both bilateral and multilateral trade are very similar. 


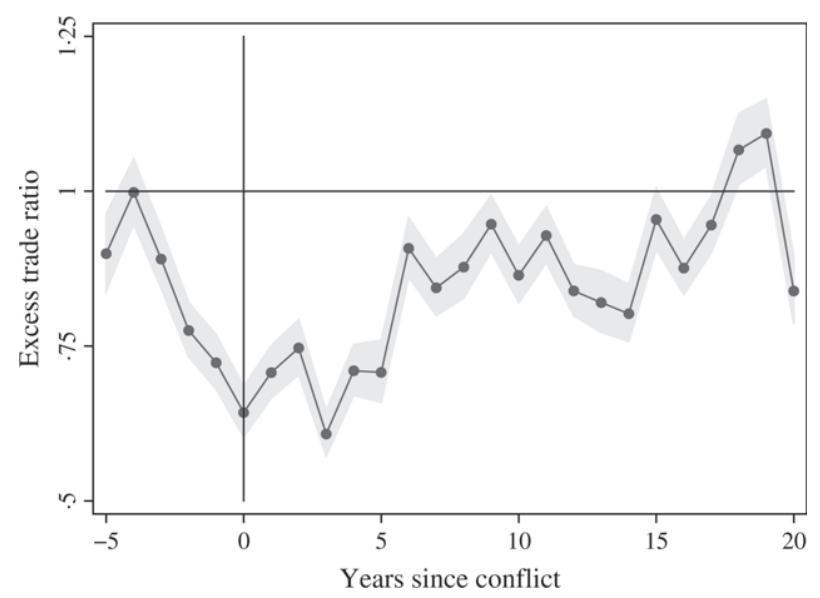

FIGURE 4

The impact of a conflict on bilateral trade

$i$ and $j$, we use the simple arithmetic average of bilateral import flows over GDP as a measure of bilateral openness. For multilateral trade openness, we use the arithmetic average of total imports of the two countries excluding their bilateral imports divided by their GDPs. We then estimate the probability of $\mathrm{MID}_{i j t}$ between countries $i$ and $j$ at time $t$ with a logit model:

$$
\operatorname{Pr}\left(\mathrm{MID}_{i j t}\right)=\gamma_{0}+\gamma_{1} \text { controls }_{i j t}+\gamma_{2} \ln \left(\frac{m_{i j t}}{E_{i t}}+\frac{m_{j i t}}{E_{j t}}\right)+\gamma_{3} \ln \left(\sum_{h \neq j, i}^{R} \frac{m_{i h t}}{E_{i t}}+\frac{m_{j h t}}{E_{j t}}\right) .
$$

Equation (9) of our theoretical model predicts $\gamma_{2}<0$ and $\gamma_{3}>0$ : a negative impact of bilateral trade openness on the probability of MID but a positive impact of multilateral trade openness on this probability. When estimating equation (14), we face three problems: observability of disputes, endogeneity of trade variables, and measurement error on trade.

1. Cross-sectional variation of disputes:

Equation (9) of our theoretical model generates implications on how the process of escalation of disputes into actual conflicts (MIDs) is affected by trade patterns. This prediction is not directly testable because the escalation process is not observed in isolation. In our data set, only the final outcome, MIDs (i.e. $\mathrm{MID}_{i j t}=0$ or 1 ), is observed. The probability that an MID occurs is the probability of a dispute between countries $i$ and $j$ multiplied by the conditional probability of escalation. With time subscripts, equation (10) becomes:

$$
\operatorname{Pr}\left(\mathrm{MID}_{i j t}\right)=\operatorname{Pr}\left(\text { dispute }_{i j t}\right) \times \operatorname{Pr}\left(\text { escalation }_{i j t} \mid \text { dispute }_{i j t}\right) .
$$

It is therefore essential in our regressions to take into account the cross-sectional variation of disputes. The estimates will be severely biased if we impose identical coefficients for all country pairs, whether they have a low probability or high probability of disputes. There are several determinants of disputes, but the one we will emphasize is bilateral distance. This seems natural as most interstate disputes are related to disagreements about borders, ethnic minorities, or religion. This view is supported by our data set: Between 1950 and 2000, the probability of MID is around 5\% for countries with a bilateral distance below $1000 \mathrm{~km}$; this probability drops to countries separated by more than $1000 \mathrm{~km}$. To 


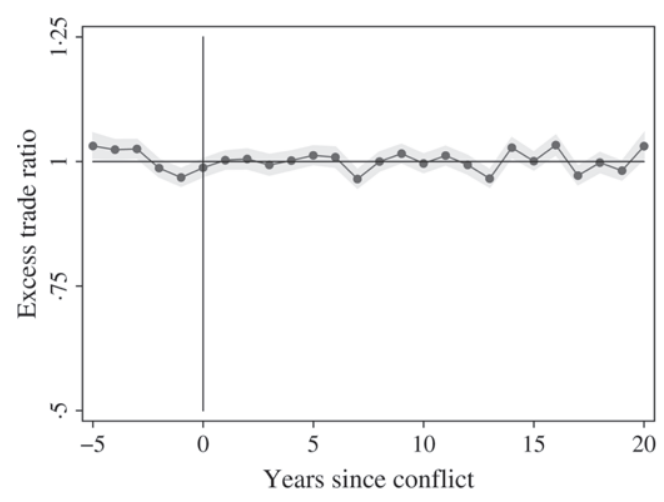

(a) Impact on total exports

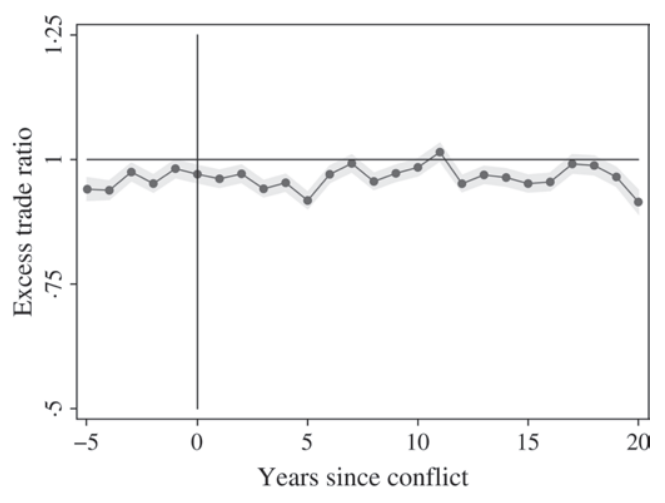

(b) Impact on total imports

FIGURE 5

The impact of a militarized interstate dispute on multilateral trade

address the issue that not all country pairs have the same probability of disputes, we first restrict the sample to those country pairs that are most likely to have a high probability of disputes, namely those with a border and those with a bilateral distance below $1000 \mathrm{~km}$. This strategy has two drawbacks: The sample is very much reduced and it assumes that, within the restricted sample, the trade coefficients are constant. Our second and more convincing strategy is to keep the full sample of countries and to add interaction terms between distance and trade variables, a natural choice given the multiplicative form in equation (15). Here, we identify our effects on the coefficients of trade and on their interaction terms. If disputes decrease with distance, we expect a positive sign on the interaction term between distance and bilateral trade and a negative one for the second interaction term between distance and multilateral trade.

2. Endogeneity:

The most obvious endogeneity issue relates to the relation between bilateral trade and military conflicts. A negative correlation between bilateral trade openness and the probability of bilateral military conflicts can arise with causality running both ways. Note that for the relation between multilateral trade openness and the probability of bilateral conflicts, the issue of reverse causality is not so obvious as we expect a positive impact of multilateral trade openness on this probability. If anything, bilateral conflicts have a slightly negative impact on multilateral trade openness (see previous section). We estimate equation (14) in three different ways in order to deal with endogeneity issues. First, based on results from the preceding section, we take a 4-year lag for bilateral and multilateral openness variables in order to limit contemporaneous reverse causality. We also control for several variables that could be co-determinants of conflicts and trade patterns. It might still be argued that omitted variables could cause both lagged trade to fall and conflicts to rise over time, even though the preceding section did not find strong evidence for this. The bias may come for instance from the fact that some countries (because of cultural, historical, or other reasons that we cannot fully control for) have good bilateral relations and large trade flows while also having a low probability of military conflict. In a second set of regressions, we thus control for such country pair fixed effects by exploiting the panel dimension of our data set. Last, we implement an instrumental variable strategy in order to control for unobserved, but time-varying, co-determinants of trade and conflicts. 


\section{Measurement error:}

Measurement error on bilateral trade data is likely to be non-negligible for countries that are involved in a military conflict, especially for bilateral trade flows with their opponent. Lagging by 4 years the trade variables alleviates part of the problem. But it does not fix it completely because some MIDs may last more than 4 years or may be recurrent: In that case, bilateral trade is permanently ill measured. Due to such measurement error we should expect the coefficient of bilateral trade to be biased toward 0 . This concern is more severe in country pair fixed effect regressions than in the cross-sectional logit. Indeed, in the former, coefficients are identified using time variations of bilateral trade within a given pair of countries. This is likely to be less accurately measured than the main source of variation we exploit in the simple logit, namely the variation of bilateral trade between fighting and non-fighting dyads. Our instrumental variables strategy also helps to alleviate this measurement error problem.

3.3.2. Results. Table 3 shows both the pooled logit results (first four columns) and the fixed effects results (last two columns). They pool a very large number of country pairs over roughly half a century each. The error term is thus likely to exhibit correlation patterns for a given country pair, and we cluster the (robust) S.E. at the pair level to take this into account. As is classical in political science, we control for the number of peaceful years (since the last MID) between the two countries. We also control in all regressions (except those with fixed effects where all controls that are not time varying are dropped) for bilateral weighted distance and contiguity between the two countries as they are natural (negative and positive, respectively) co-determinants of military conflict and trade.

In the first three regressions, we want to present very simple raw estimates of our main theoretical results. In the first two regressions, we take into account the cross-sectional variation of disputes by restricting our sample to country pairs with the highest probability of disputes that could escalate into a military conflict: contiguous pairs (regression 1) and contiguous pairs with a bilateral weighted distance below $1000 \mathrm{~km}$ (regression 2). In this very restricted sample, the signs on the trade variables are the expected ones even though not significant for multilateral openness in regression 1 . In regression 3 , we use the full sample of country pairs but with interaction terms between distance and trade variables. In this case, all coefficients on the trade variables (interacted or not) have the expected sign and are significant at the $1 \%$ level.

Regression 4 includes a long list of controls that can affect both trade flows and the probability of military conflicts. We first include year dummies (coefficients unreported) to control for the overall potential co-evolution of MIDs and international trade over time. We also systematically control for the temporal autocorrelation in wars by including a set of 20 different dummies (coefficients unreported) equal to 1 when the country pair was in MID in $t-1, t-2, \ldots t-20$. This is crucial because we have seen in section 3.2 that the effect of a military conflict on trade flows can be long lasting. All regressions throughout the rest of the empirical analysis will include the time dummies and the set of 20 dyadic past war dummies. As an additional control for temporal autocorrelation in wars, we also consider hereafter a set of 20 different dummies which code for the fact that the current MID at time $t$ was already active (without any interruption) in time $t-1, t-2, \ldots t-20$; however, such dummies being perfect predictors of current war, they cannot be included in our logit specifications and thus are estimated only in our linear specifications (column 6 in Table 3 and all columns in Tables 6 and 7-coefficients unreported). We further introduce a dummy for all observations for which trade flows (both exports and imports) are reported as zero by the IMF (these are not missing values). We view the dummy of zero trade observations as a control for trade costs interpreted as fixed costs. We also control for the index of similarity of language, the existence of a preferential trade area, and the number of GATT/WTO 
TABLE 3

Impact of trade on military conflict-I (benchmark results)

\begin{tabular}{|c|c|c|c|c|c|c|}
\hline & \multicolumn{6}{|c|}{ Dependent variable: MID } \\
\hline & Model (1) & Model (2) & Model (3) & Model (4) & Model (5) & Model (6) \\
\hline ln bil. openness $t-4$ & $\begin{array}{c}-0.090 * * * \\
(0.032)\end{array}$ & $\begin{array}{l}-0.127 * * \\
(0.050)\end{array}$ & $\begin{array}{c}-0.851 * * * \\
(0.163)\end{array}$ & $\begin{array}{c}-0 \cdot 236 * \\
(0.132)\end{array}$ & $\begin{array}{c}0 \cdot 271 \\
(0 \cdot 178)\end{array}$ & $\begin{array}{l}-0.003 \\
(0.009)\end{array}$ \\
\hline ln mult. openness $t-4$ & $\begin{array}{c}0.039 \\
(0.106)\end{array}$ & $\begin{array}{l}0 \cdot 275 * * \\
(0 \cdot 124)\end{array}$ & $\begin{array}{c}1.922 * * * \\
(0.556)\end{array}$ & $\begin{array}{l}1.520 * * * \\
(0.451)\end{array}$ & $\begin{array}{c}1.315 * * \\
(0.585)\end{array}$ & $\begin{array}{l}0 \cdot 159 * * * \\
(0 \cdot 030)\end{array}$ \\
\hline Number of peaceful years & $\begin{array}{c}-0.070 * * * \\
(0.011)\end{array}$ & $\begin{array}{c}-0.060 * * * \\
(0.014)\end{array}$ & $\begin{array}{c}-0.067 * * * \\
(0.006)\end{array}$ & $\begin{array}{c}-0.019 * * * \\
(0.002)\end{array}$ & $\begin{array}{l}0.014 * * * \\
(0.002)\end{array}$ & $\begin{array}{l}0 \cdot 002 * * * \\
(0 \cdot 000)\end{array}$ \\
\hline In distance & $\begin{array}{l}-0 \cdot 088 \\
(0 \cdot 111)\end{array}$ & $\begin{array}{c}0.206 \\
(0.222)\end{array}$ & $\begin{array}{l}-0.063 \\
(0 \cdot 220)\end{array}$ & $\begin{array}{c}-0.835 * * * \\
(0.174)\end{array}$ & & \\
\hline Contiguity & & & $\begin{array}{c}1.393 * * * \\
(0.180)\end{array}$ & $\begin{array}{c}1 \cdot 107 * * * \\
(0 \cdot 171)\end{array}$ & & \\
\hline ln distance $\times \ln$ mult. open & & & $\begin{array}{c}-0.303 * * * \\
(0.075)\end{array}$ & $\begin{array}{c}-0.189 * * * \\
(0.057)\end{array}$ & $\begin{array}{c}-0.146 * \\
(0.075)\end{array}$ & $\begin{array}{c}-0.018 * * * \\
(0.003)\end{array}$ \\
\hline ln distance $\times \ln$ bil. open & & & $\begin{array}{l}0 \cdot 118 * * * \\
(0 \cdot 021)\end{array}$ & $\begin{array}{c}0.038 * * \\
(0.017)\end{array}$ & $\begin{array}{l}-0.034 \\
(0 \cdot 024)\end{array}$ & $\begin{array}{c}0.000 \\
(0 \cdot 001)\end{array}$ \\
\hline Dummy for zero trade $t-4$ & & & & $\begin{array}{l}-0.291 * \\
(0.155)\end{array}$ & $\begin{array}{c}0 \cdot 249 \\
(0 \cdot 173)\end{array}$ & $\begin{array}{c}0 \cdot 002 \\
(0 \cdot 004)\end{array}$ \\
\hline UN vote correlation $t-4$ & & & & $\begin{array}{c}-0.952 * * * \\
(0.142)\end{array}$ & $\begin{array}{c}-0 \cdot 610 * * * \\
(0 \cdot 197)\end{array}$ & $\begin{array}{c}-0.022 * * * \\
(0.006)\end{array}$ \\
\hline Sum of democracy indexes & & & & $\begin{array}{c}-0.283 * * \\
(0.116)\end{array}$ & $\begin{array}{l}-0 \cdot 136 \\
(0 \cdot 179)\end{array}$ & $\begin{array}{c}0 \cdot 003 \\
(0 \cdot 005)\end{array}$ \\
\hline \# other wars in $t$ & & & & $\begin{array}{l}0 \cdot 240 * * * \\
(0 \cdot 011)\end{array}$ & $\begin{array}{l}0 \cdot 256 * * * \\
(0 \cdot 012)\end{array}$ & $\begin{array}{c}0 \cdot 035 * * * \\
(0 \cdot 001)\end{array}$ \\
\hline ln distance to nearest war in $t$ & & & & $\begin{array}{c}0.006 \\
(0.070)\end{array}$ & $\begin{array}{c}-0.197 * * \\
(0.095)\end{array}$ & $\begin{array}{c}-0.008 * * * \\
(0.003)\end{array}$ \\
\hline Sum $\ln$ areas & & & & $\begin{array}{c}0 \cdot 159 * * * \\
(0 \cdot 025)\end{array}$ & & \\
\hline Alliance active in $t$ & & & & $\begin{array}{c}0.092 \\
(0.110)\end{array}$ & $\begin{array}{l}-0 \cdot 028 \\
(0 \cdot 196)\end{array}$ & $\begin{array}{c}-0.023 * * \\
(0.011)\end{array}$ \\
\hline Common language & & & & $\begin{array}{l}0.243 * \\
(0.128)\end{array}$ & & \\
\hline Pair ever in colonial relationship & & & & $\begin{array}{l}0.359 * \\
(0.205)\end{array}$ & & \\
\hline Common colonizer & & & & $\begin{array}{c}0.091 \\
(0.172)\end{array}$ & & \\
\hline Free trade area (full set) & & & & $\begin{array}{l}-0 \cdot 205 \\
(0 \cdot 170)\end{array}$ & $\begin{array}{l}-0 \cdot 066 \\
(0 \cdot 306)\end{array}$ & $\begin{array}{c}-0.023 * \\
(0.012)\end{array}$ \\
\hline \# of GATT members in dyad & & & & $\begin{array}{c}0 \cdot 107 \\
(0 \cdot 081)\end{array}$ & $\begin{array}{c}-0 \cdot 30 * \\
(0 \cdot 155)\end{array}$ & $\begin{array}{l}-0 \cdot 004 \\
(0 \cdot 004)\end{array}$ \\
\hline$N$ & 7826 & 4558 & 223,788 & 223,788 & 12,770 & 223,788 \\
\hline Pseudo- $R^{2}$ & $0 \cdot 175$ & $0 \cdot 188$ & $0 \cdot 328$ & $0 \cdot 547$ & $0 \cdot 328$ & $0 \cdot 401$ \\
\hline Sample & $\begin{array}{l}\text { Contiguous } \\
\text { pairs }\end{array}$ & $\begin{array}{l}\text { Contiguous pairs } \\
\text { and }<1000 \mathrm{~km}\end{array}$ & Full & Full & Full & Full \\
\hline Time dummies & No & No & No & Yes & Yes & Yes \\
\hline Dyadic war lags & No & No & No & Yes & Yes & Yes \\
\hline Dyadic same war lags & No & No & No & No & No & Yes \\
\hline Estimation method & Logit & Logit & Logit & Logit & FE logit & FE LPM \\
\hline
\end{tabular}

Notes: S.E. in parentheses with $* * *, * *$, and $*$, respectively, denoting significance at the $1 \%, 5 \%$, and $10 \%$ levels. Time dummies and lagged MIDs (20 years) are not reported. Column 1: contiguous country pairs only. Column 2: proximate countries only. Column 3: full sample with interaction term. Column 4: full sample with interaction term and complete control set. Column 5: full sample with country pair fixed effects logit model. Column 6: full sample with country pair fixed effects linear probability model (LPM). S.E. clustered by country pair. MID = militarized interstate dispute. 
members in the country pair. We add a control for country pairs which had a colonial relationship and a control for those with a common colonizer. We introduce these controls because the empirical trade literature around the gravity equation has shown that they affect trade flows. Because they are related to the cultural, historical, political, and institutional ties between countries, they may also affect the probability of military conflicts.

We also add political controls which are possible determinants of MID and which could be correlated with trade flows. The sum of areas of the two countries (in log) is introduced as large countries are typically countries with important minorities that can be the source of conflicts with neighbouring nations. Large countries may also be more difficult to defend, making them potential targets to frequent attacks. Larger countries are also naturally less open to trade. We also control for the political regime. Indeed, the democratic peace hypothesis, which has been studied by both political scientists and economists (see Levy and Razin, 2004, for a recent explanation of the hypothesis) states that democratic countries are less prone to violence. But democratic countries are also more open to trade. We control for two (time-varying) measures of political affinity between countries that may affect both the probability of MID and the bilateral trade: UN vote correlation (lagged by 4 years) and a dummy for those country pairs belonging to a military alliance. Finally, it is important to control for the cross-sectional serial correlation of wars; indeed, the existence of other wars may affect both the probability of a bilateral war and trade patterns. At the country pair level, we do this in two different ways: by including the distance to the nearest current war which does not involve a country from the pair and by including the total number of MIDs (excluding their potential bilateral MID) which the countries of the pair are involved in at time $t$. More detail on all data sources is available in Appendix 4.

With all these controls, regression 4 remains supportive of our theoretical predictions as all trade variables have the right sign and are significant at the $1 \%$ level except the bilateral trade variable which is significant at the $10 \%$ level only. An increase in bilateral openness decreases the probability of MID but less so for distant countries. A high level of multilateral trade openness raises the probability of MID mostly for proximate countries. This is consistent with our theoretical framework and suggests that trade patterns (bilateral and multilateral trade openness) affect more the probability of military conflicts of proximate countries because they mostly affect the probability of escalation rather than the probability of disputes. Hence, if, as suggested by our theory, globalization increases the probability of escalation for any given pair of countries, it does so mostly for countries that have a high probability of disputes, that is proximate countries. This, we argue, may be an explanation for the trend towards more local conflicts as illustrated by Figure 2 .

In the next two columns, we replicate specification (4) and add country pair fixed effects. We do it first with a fixed effect logit specification in which case, only those country pairs that had a military conflict during the period can be retained. We then proceed with a standard linear fixed effect specification for which the whole sample can be used. Given the measurement error issue for bilateral trade of country pairs that have had an MID during the period, these fixed effect estimations serve mostly to test the impact of multilateral trade on the probability of conflict in the time dimension. The multilateral trade variable is significant at $5 \%$ or $1 \%$ in regressions (5) and (6).

In Tables 4 and 5, we perform numerous robustness checks on our preferred pooled regression (corresponding to column (4) of Table 3). For the sake of exposition, we report in these tables only the coefficients of the main variables. In the first column, we restrict the definition of MIDs to the conflicts of highest intensity (4 and 5), that is those that are characterized by the use of force and war per se (defined as more than 1000 military deaths). In column (2), we restrict the definition of MIDs to level 5 conflicts only. In both cases, the trade coefficients have the same sign as in the benchmark regression. The significance of the bilateral trade 
TABLE 4

Impact of trade on MID—II (robustness checks)

\begin{tabular}{|c|c|c|c|c|c|}
\hline & \multicolumn{5}{|c|}{ Dependent variable: MID } \\
\hline & Model (1) & Model (2) & Model (3) & Model (4) & Model (5) \\
\hline ln bil. openness $t-4$ & $\begin{array}{l}-0 \cdot 138 \\
(0 \cdot 155)\end{array}$ & $\begin{array}{c}-0.699 * \\
(0.410)\end{array}$ & $\begin{array}{l}-0 \cdot 195 \\
(0 \cdot 131)\end{array}$ & $\begin{array}{l}-0 \cdot 214 \\
(0 \cdot 133)\end{array}$ & $\begin{array}{c}-0.221 * \\
(0.134)\end{array}$ \\
\hline ln mult. openness $t-4$ & $\begin{array}{l}1 \cdot 181 * * * \\
(0 \cdot 414)\end{array}$ & $\begin{array}{c}2 \cdot 062 * * \\
(1.001)\end{array}$ & $\begin{array}{l}1.461 * * * \\
(0.461)\end{array}$ & $\begin{array}{c}1.536 * * * \\
(0.451)\end{array}$ & $\begin{array}{c}1.627 * * * \\
(0.477)\end{array}$ \\
\hline ln distance $\times \ln$ mult. open & $\begin{array}{c}-0.168 * * * \\
(0.051)\end{array}$ & $\begin{array}{c}-0.323 * * * \\
(0.119)\end{array}$ & $\begin{array}{c}-0.181 * * * \\
(0.059)\end{array}$ & $\begin{array}{c}-0.196 * * * \\
(0.057)\end{array}$ & $\begin{aligned}-0 \cdot 201 * * * \\
\\
(0 \cdot 061)\end{aligned}$ \\
\hline $\ln$ distance $\times \ln$ bil. open & $\begin{array}{c}0.026 \\
(0.021)\end{array}$ & $\begin{array}{c}0.062 \\
(0.051)\end{array}$ & $\begin{array}{l}0.031 * \\
(0.017)\end{array}$ & $\begin{array}{c}0.035 * * \\
(0 \cdot 017)\end{array}$ & $\begin{array}{l}0.036 * * \\
(0.017)\end{array}$ \\
\hline Security council & & & $\begin{array}{c}0.313 * * \\
(0.159)\end{array}$ & & \\
\hline Communist regime & & & $\begin{array}{l}-0 \cdot 183 \\
(0 \cdot 151)\end{array}$ & & \\
\hline One country is oil exporter & & & & $\begin{array}{l}0.609 * \\
(0.314)\end{array}$ & \\
\hline Oil exporter $\times 60 \mathrm{~s}$ & & & & $\begin{array}{l}-0.273 \\
(0.438)\end{array}$ & \\
\hline Oil exporter $\times 70 \mathrm{~s}$ & & & & $\begin{array}{l}-0 \cdot 288 \\
(0 \cdot 349)\end{array}$ & \\
\hline Oil exporter $\times 80 \mathrm{~s}$ & & & & $\begin{array}{l}-0.303 \\
(0.353)\end{array}$ & \\
\hline Oil exporter $\times 90 \mathrm{~s}$ & & & & $\begin{array}{c}-0.671 * \\
(0.362)\end{array}$ & \\
\hline Max of primary exports share of GDP & & & & & $\begin{array}{c}1.170 \\
(0 \cdot 899)\end{array}$ \\
\hline Primary exports share $\times 60$ s & & & & & $\begin{array}{l}-0.592 \\
(1.255)\end{array}$ \\
\hline Primary exports share $\times 70 \mathrm{~s}$ & & & & & $\begin{array}{l}-0.453 \\
(0.998)\end{array}$ \\
\hline Primary exports share $\times 80$ s & & & & & $\begin{array}{l}-0.798 \\
(0.937)\end{array}$ \\
\hline Primary exports share $\times 90$ s & & & & & $\begin{array}{l}-1.261 \\
(0.956)\end{array}$ \\
\hline Time and past war dummies & Yes & Yes & Yes & Yes & Yes \\
\hline$N$ & 223,788 & 142,523 & 223,788 & 223,788 & 218,763 \\
\hline Pseudo- $R^{2}$ & $0 \cdot 552$ & $0 \cdot 674$ & $0 \cdot 548$ & $0 \cdot 548$ & $0 \cdot 55$ \\
\hline
\end{tabular}

Notes: S.E. in parentheses with $* * *, * *$, and $*$, respectively, denoting significance at the $1 \%, 5 \%$, and $10 \%$ levels. Time dummies are not reported as well as the same controls as in column (4) of Table 3. S.E. clustered by dyad. Column 1: only MIDs of levels 4 and 5. Column 2: only MIDs of level 5. Estimation is by logit on the same sample as column (4) of Table 3. MID = militarized interstate dispute.

variable decreases due to the more restrictive definition of MID. Note also that when conflicts are restricted to level 5 only, we lose many observations (around 80,000) because some year dummies are perfect predictors of the absence of war, which implies to drop those years. ${ }^{17}$ These results suggest that the definition of MID we adopt throughout the paper (i.e. conflict of intensities 3, 4, and 5) is not a major source of bias in our estimates. In regression (3) we add a dummy for "major powers" which we define as those five countries (U.S., U.K., France, China, and Russia) endowed with a permanent seat in the UN's Security Council. We also add dummies for communist countries as we know that these regimes have been less opened to trade over our

17. In unreported regressions available on request, we reduce the number of time dummies and replace the yearly time dummies by dummies indicating 2 -year periods in order to keep more observations. The coefficients of interest are almost unaffected. 
TABLE 5

Impact of trade on wars-III (robustness checks continued)

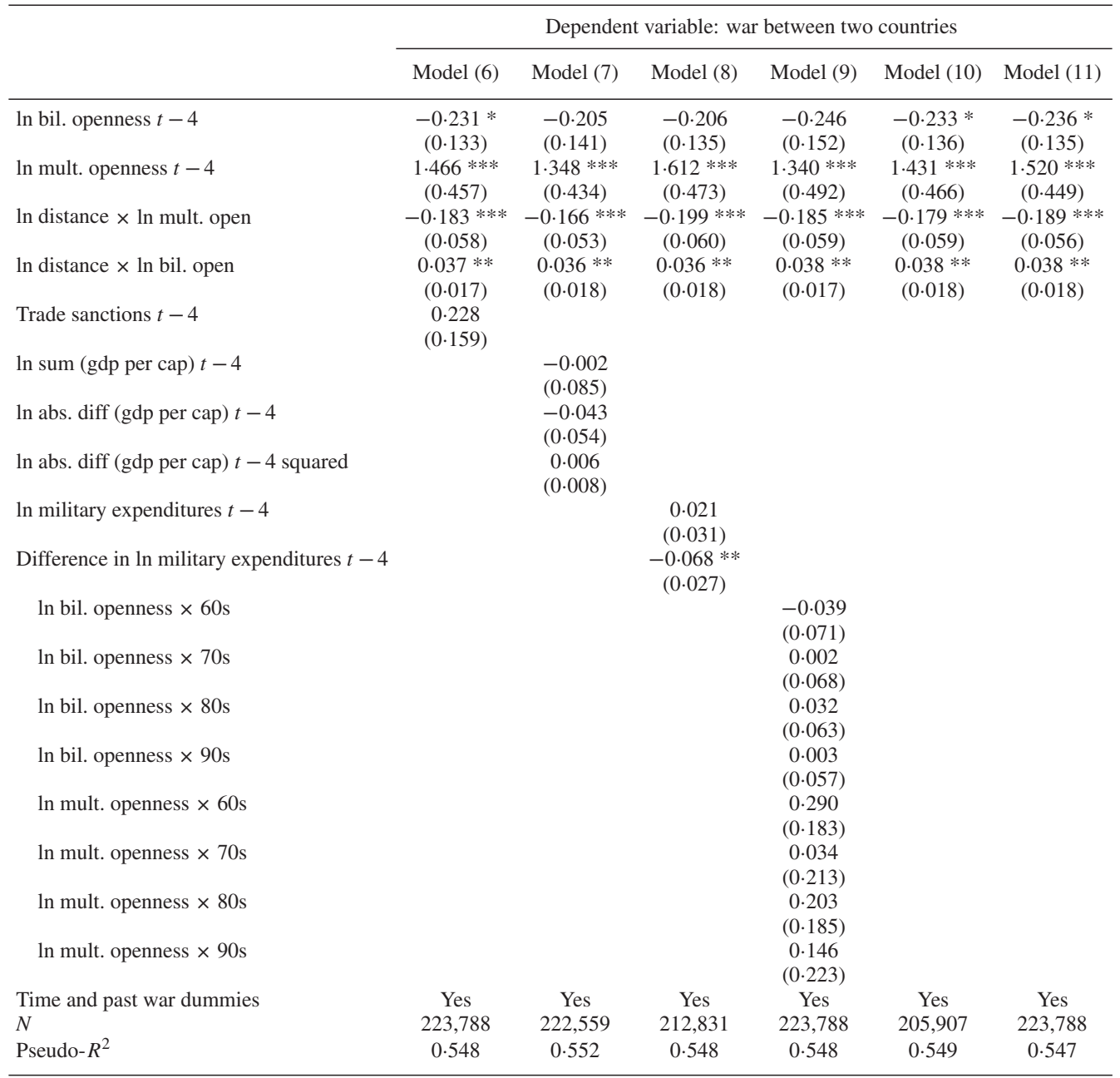

Notes: S.E. in parentheses with $* * * * *$, and $*$, respectively, denoting significance at the $1 \%, 5 \%$, and $10 \%$ levels. Robust S.E. clustered by dyad. Estimation is by logit on the same sample as column (4) of Table 3. Time dummies are not reported as well as the same controls as in column (4) of Table 3. Column (10): sample restricted to dyads with at least 30 years of data. Column (11): multi-way clustering by dyad and year following the Cameron et al. (2006) method.

sample period. The trade results are not driven by either group. In column (4), we add a dummy if one of the two countries is an oil exporting country as defined by the IMF in the DOTS data set. The reason is that oil exporting countries may be more open to trade and also more prone to conflicts to defend these resources. Hence, these countries may drive our results on multilateral trade. Also, to control for changes in oil prices that may affect trade openness of these countries as well as their propensity to enter in conflicts, we include interaction dummies between the oil exporter dummy and decades. As expected, oil exporting countries are more often involved in conflicts, but the multilateral trade variable remains significant at the $1 \%$ level. In column (5), we perform the same exercise but we use the highest share of primary goods' exports in the GDP of the country pair. We obtain similar results. In regression (6) of Table 4, we add a dummy that 
designates those country pairs for which trade sanctions (lagged 4 years) are reported by Elliot et al. (2005). These authors show that trade sanctions lead to a substantial decrease in trade. Such sanctions also reflect bad political relations between countries which can escalate into conflicts. Hence, the negative effect of bilateral trade on conflicts could be spurious and generated by the effect of trade sanctions on trade that would also predict future conflicts. The effects of bilateral and multilateral trade openness remain robust. In regression (7), we control for the level and difference in GDP per capita within a pair of countries as well the square of this difference so as to allow for non-linearity in the relation. If richer countries are more open to trade and are also more prone to warfare, then our positive link between multilateral trade openness and the probability of conflict could be spurious. This does not seem to be the case. In regression (8), we control for military expenditures as countries at war may import more weapons which may explain the positive sign on multilateral trade in our regression. We do not have data on trade in weapons, but military expenditures should proxy for this. We add controls for the log of the sum of the level of reported military expenditures and the log of the difference of military expenditures. In this specification, the multilateral trade coefficient remains significant at the $1 \%$ level. In regression (9), we add interaction terms between our two trade variables and decade dummies. We do this to check whether our results are driven by a specific period in our sample such as the decolonization, the Cold War, or the end of the Cold War. The results suggest that no specific decade drives our results. In regression (10), we restrict the sample to those countries with at least 30 years of data. The results again are robust. Finally, column (11) reports results using a new technique for the clustering of the error terms. All other columns report S.E. with a dyadic-level clustering, which is a standard option in the econometric package we use (Stata). It might be argued that - in addition to the dyadic dimension - there could remain serial autocorrelation of errors within time periods. This calls for multi-way clustering for both dyad and year separately but in the same regression. Because these clusters are not nested, this is a more complicated problem than the one-way clustering. A very recent paper by Cameron et al. (2006) proposes a multi-way clustering method, which involves re-computing the correct variance-covariance matrix out of the ones obtained from different one-way clustering regressions (see their paper and in particular pages 12-13 for the binary dependent variable case). We implement their method in our benchmark regression and observe that the S.E. hardly change at all. Practically, in our sample, the dyadic one-way clustering is by far the most important adjustment. Overall, we interpret these results as very supportive of our theoretical predictions. The result of a positive impact of multilateral trade openness on the probability of conflict is very robust. The negative impact of bilateral trade on the probability of conflict is somewhat less robust in terms of statistical significance, although the magnitude of the coefficient is very stable. We interpret this as a problem of measurement errors that certainly plague bilateral trade data for country pairs that experience military conflicts. The instrumental variable strategy that we implement in Section 3.5 is partly meant to address this issue.

\subsection{Quantification}

We now want to quantify the magnitude of the effect of trade on the probability of military conflict between two countries. First, note that since our principal variables of interest are in logs, each coefficient is a very close approximation of the elasticity of war probability with respect to a change in the considered variable from a given start value, for instance the mean or median. ${ }^{18}$

18. The exact formula for this elasticity is $\beta(1-\bar{P})$, where $\beta$ is the obtained coefficient and $\bar{P}$ is the war probability given by the logit formula. A natural thought experiment is to consider $\bar{P}$ to be the probability when all variables are at their average or median values (typically a very small figure in our case).

(C) 2008 The Review of Economic Studies Limited 
The interpretation of coefficients in terms of economic magnitude is, however, here made difficult by the terms interacting openness with distance. As emphasized by Ai and Norton (2003), the non-linear nature of logit estimation makes it impossible to make the usual linear adjustment to coefficients for different levels of distance. ${ }^{19}$

In order to judge whether our results are quantitatively important, we therefore follow a different approach. Using the estimates from our preferred regression (4 in Table 3), we simulate the effect of changes in different variables, holding everything else constant, on the predicted probability of conflict obtained from the logit model. Of particular interest for us is the following counterfactual: What would happen to probabilities of conflict should the countries come back to the level of bilateral and multilateral openness they had at the start of the current globalization phase? We therefore calculate the predicted probabilities of war for our benchmark model in the year 2000 and then compute the same probabilities when the different trade variables are brought back to their level of 1970. These different probabilities are then averaged over four groups of countries depending on their bilateral distance: less than $1000 \mathrm{~km}$, between 1000 and $2000 \mathrm{~km}$, between 2000 and $5000 \mathrm{~km}$, and more than $5000 \mathrm{~km}$.

Results are depicted in Figure 6. The baseline average probability of a military conflict in 2000 is $4.46 \%$ for countries separated by a bilateral distance shorter than $1000 \mathrm{~km}$. For the second bar, we simulate the effect of bringing the level of bilateral trade openness back to its 1970 level (while all other variables are kept at their 2000 level). The average conflict probability would increase to $4.81 \%$. In the case of multilateral trade openness, the return to the 1970 level would lower the probability of a military conflict to $3.41 \%$ (the third bar). The effects for the most proximate countries are therefore estimated to be quite large. Even though it is interesting to quantitatively disentangle the two effects of bilateral and multilateral trade, the globalization process is by construction an increase in both bilateral and multilateral trade flows. Hence, the overall net effect is the one that we want to focus on: This is shown in the fourth bar which suggests that the globalization process between 1970 and 2000 has increased the probability of a military conflict between two proximate countries from $3.67 \%$ to $4.46 \%$, an increase of $21 \%$. This is surprisingly large for this group of countries. However, note first that the effects are much smaller for countries with higher bilateral distance (the next three blocks of columns in Figure 6). In addition, the increase in trade openness is itself large during this period for the median country pair of this short-distance group: $154 \%$ for the bilateral trade openness ratio and $60 \%$ for the multilateral trade openness ratio in our sample. For comparison purposes, the last bar of each group shows the marginal effect (on the probability of conflict in 2000) of adding 20 peaceful years in the bilateral political relationship. In terms of its effect on the probability of a military conflict, 30 years of globalization has roughly had the same effect as eliminating 20 years of peace in the bilateral relation between proximate countries. Note finally that the empirical finding that the net effect of 30 years of globalization has been to increase the probability of a bilateral military conflict is consistent with Result 1 of the theoretical section.

For countries with a bilateral distance between 1000 and $2000 \mathrm{~km}$, the effects are qualitatively similar but quantitatively much smaller. They become extremely small for countries with a bilateral distance larger than $2000 \mathrm{~km}$. That the impact of trade patterns on the probability of conflicts decreases with distance is consistent with our theoretical framework. It is also consistent with the increased "localization" of military conflicts as illustrated by Figure 2. Hence, we conclude that 30 years of globalization has significatively increased the probability of military conflicts during this period but only for proximate countries for which the probability of a dispute is the highest.

19. We thank Harry Bowen for pointing out this issue. 


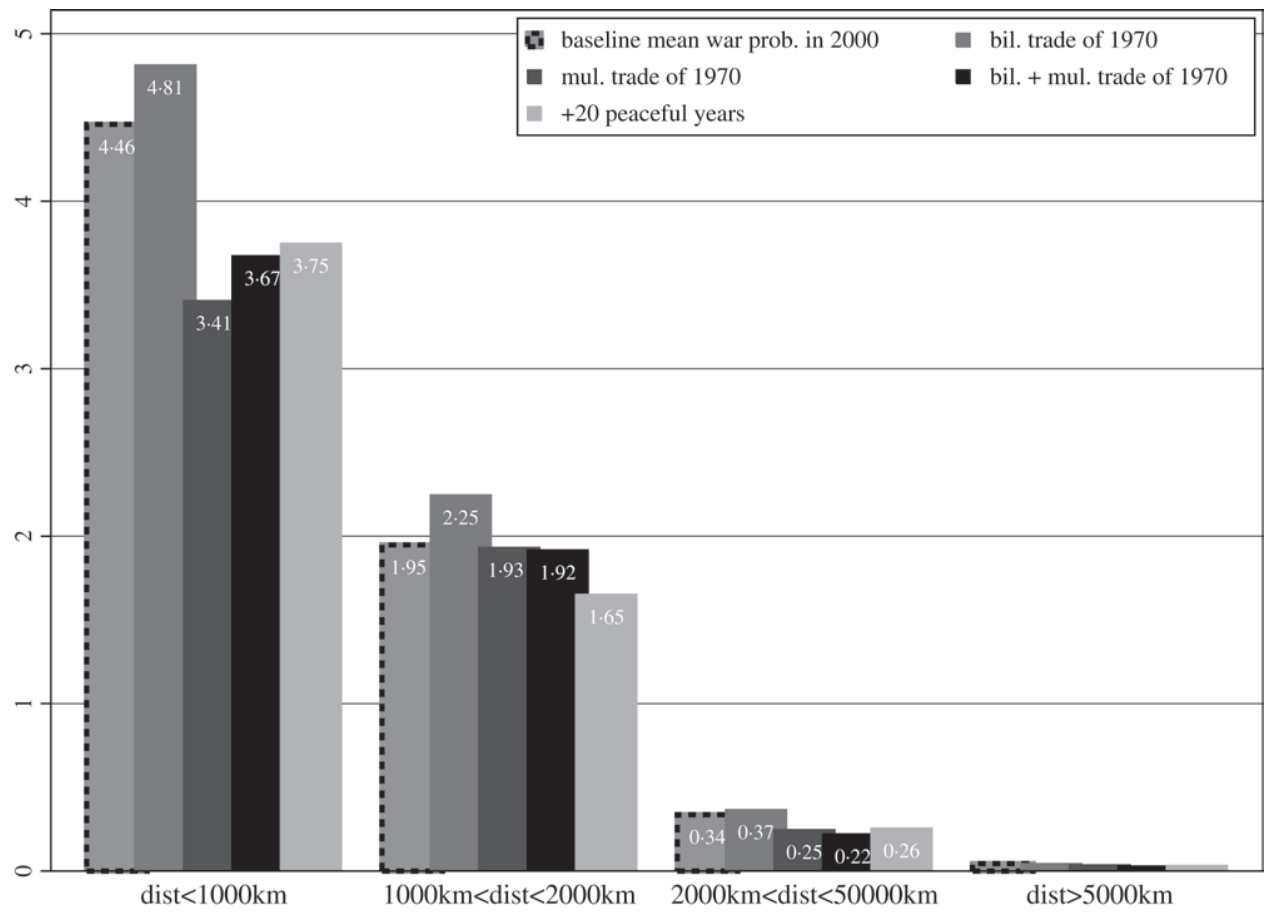

FIGURE 6

Quantifying the impact of bilateral and multilateral trade on conflicts

\subsection{Instrumental variables}

In this section, ${ }^{20}$ we implement an instrumental variable strategy to control for potential endogeneity of trade as an explanation of armed conflicts. Given that there are two potentially endogenous variables (bilateral and multilateral trade openness), the objective is to find two time-varying instruments that impact trade flows but are not affected directly by the bilateral relation of two countries for which we want to estimate the probability of an MID. These two instruments are the Generalized System of Preferences (GSP) and an index of economic remoteness of the two countries.

The GSP, which consists of schemes of tariff preferences granted by developed countries to developing countries, is well fitted for our purpose. It facilitates access of least developed countries (LDCs) to markets of rich countries. ${ }^{21}$ The first GSP schemes were implemented by the European Economic Community and Japan in 1971 and by the U.S. in 1976; the number of beneficiary countries rose dramatically in the 1980's and early 1990's. All GSP schemes provide tariff concessions on a wide range of products. GSP programmes resulted in a substantial increase in LDCs' trade (for empirical evidence, see Baldwin and Murray, 1977; Rose, 2004; Romalis, 2003). LDCs' eligibility to GSP programmes is primarily based on their level of poverty. In particular, there is no official condition imposed on the beneficiary country's propensity to enter into military conflicts. This last point is crucial to our instrumentation strategy: A valid instrument should have no direct relationship with the dependent variable (conflicts here). Despite these official rules, GSP participation might in reality be linked to political objectives of granting countries.

20. We thank Jean-Marc Robin for his numerous suggestions and comments on this section.

21. A detailed analysis of GSP schemes can be found in Romalis (2003) and UNCTAD (2003). 
It is possible that political ties between the two countries affect what remains a discretionary decision by the rich country. ${ }^{22}$ Nevertheless, regarding the validity of our instrument, what matters is the fact that GSP participation has no causal link with the beneficiary country's conflicts with countries different from the one granting the programme. This is the reason why in the following, we exclude from the sample those countries (U.S., Japan, European Union (EU) members, New Zealand, Australia, Poland, Hungary, and Bulgaria) that have at some point granted a GSP programme. We define our instrumental variable in the following way: For each country pair, we count the number of recipients of a European GSP programme and multiply this number by the combined proximity to the EU (the city of Brussels). We choose the European scheme because (1) it was the first to be implemented in 1971, (2) U.S. or Japanese schemes are less powerful instruments, and (3) there was no unified foreign policy at the European level; hence, it is hard to believe that the EU GSP scheme is used by the different members for their own foreign policy. We include the interaction with proximity to the EU because the effects of a GSP given by the EU on the trade structure are larger for nearby countries. We lag this instrumental variable by 8 years, which leaves time for the GSP programme to produce its effect on the trade structure of recipient countries at date $t-4$. For pairs of countries including a GSP recipient, we expect that the improved access to a rich and distant market is likely to exert a positive shock to multilateral trade while we expect no obvious effect on bilateral trade.

The second instrumental variable is a country pair measure of the economic remoteness to the rest of the world. This variable is routinely used in the international trade literature as one of the determinants of trade flows (Baier and Bergstrand, 2004, is a recent example). Intuitively, remoteness is an inverse measure of each importer's set of alternative sourcing countries for their imports. Due to decreased competition from the rest of the world, a pair of countries with few nearby and large alternative sources of goods (a remote pair) will alter the geographical structure of its trade through a relative increase of its bilateral imports with respect to its multilateral imports. Following the literature, our definition of the remoteness variable is:

$$
\operatorname{remoteness}_{i j t}=-\ln \left(\sum_{k \neq j, i}^{R} \frac{\mathrm{GDP}_{k t}}{d_{i k}}+\sum_{k \neq j, i}^{R} \frac{\mathrm{GDP}_{k t}}{d_{j k}}\right) .
$$

When building the remoteness variable, we exclude any third country $k$ which has been at war with one of the members $(i, j)$ of the country pair at any moment in history. We also lag the variable by 4 years. The main interest of the remoteness variable is that it varies in the time dimension because of the relative GDP growth of countries outside the country pair; therefore, it is not affected by the bilateral relation of the two countries $(i, j)$ for which we want to estimate the probability of MID. An increase in remoteness should tend to raise bilateral trade openness with respect to multilateral trade openness of the two countries.

We include country pair fixed effects and year dummies in all our instrumental variables (IV) regressions. Indeed, the purely geographical part of the remoteness index is time invariant and could be linked to the propensity to experience military conflicts. Controlling for country pair fixed effects eliminates this source of endogeneity. ${ }^{23}$ Furthermore, controlling for year dummies

22. From this perspective, a look at the history of the U.S. GSP scheme is instructive: (1) most communist countries were excluded from the U.S. scheme until the end of the Cold War and (2) while most suspensions from the U.S. programme involve countries that in fact reached a high enough level of development (e.g. Hong-Kong, Singapore, and South Korea in 1989 and Israel in 1995), there are several cases involving bad political relations between the beneficiary country and the U.S. (e.g. Nicaragua in 1985, Paraguay in 1987, and Chile in 1988).

23. Another (relatively) time-invariant source of endogeneity is that poor countries, which are the only beneficiaries of GSP programmes, could be intrinsically more prone to war. Note, however, that in regression (7) of Table 4, the level and difference in GDP per capita have no significant effect on the probability of an MID. 
is important since the GSP schemes were mostly implemented during the 1970's. We want, in this demanding specification, to be able to identify variation of conflictuality and trade patterns within country pairs over time, while controlling for an overall worldwide trend in the war probability.

Using instrumental variables' methods is not straightforward in our case since no standard estimation technique is readily available with a fixed effect logit estimation. Furthermore, such technique would, as noted for regression (5) of Table 3, imply to throw away the vast majority of informative observations where no conflict arises in our time frame. We follow one of the solutions provided by Wooldridge (2002), which is simply to use a fixed effects linear probability model.

Another concern is that medium-run political cycles (e.g. the rise of nationalism) could affect both the trade regime and the interventionist nature of governments. To deal with this potential source of endogeneity, we also present longer run tests where all variables (including time dummies and the MID variable) are lumped by decade. This enables to filter out the spurious effects of such political cycles on the correlation between trade flows and MID.

Finally, in some of our instrumented specifications, we "compact" the bilateral and multilateral trade openness variables into one single trade variable, which is expected to have a positive impact on the probability of a bilateral MID according to our theory. This variable is the country pair geographical trade structure, that is the log of the ratio of multilateral over bilateral openness. We expect GSP schemes to exert a positive shock and economic remoteness, a negative one on the country pair structure of trade. The benefit of this procedure is that it allows to perform an overidentification test since there are now two instruments for only one endogenous explanatory variable.

Table 6 shows the first-stage regressions where, as before, coefficients on dummies for time and past conflicts are not reported. The first two columns correspond to the instrumentation of bilateral and multilateral trade flows, respectively. The instruments do not suffer from statistical weakness as the coefficients of interest are highly significant in three of the four cases and the $F$-tests on the joint null effect of IVs reject the hypothesis and exceed the threshold of 10 recommended by Staiger and Stock (1997). As expected, the GSP has a positive impact on multilateral trade and no significant impact on bilateral trade. Remoteness has a positive impact on bilateral trade and, surprisingly, a positive impact on multilateral trade. However, the coefficient for multilateral trade is smaller than the coefficient for bilateral trade, confirming that the expected effect of remoteness is to re-balance the geographical structure of trade from multilateral to bilateral openness. This interpretation is confirmed in the third column, which reports the first stage for our "compact" measure of trade structure (multilateral over bilateral trade). In this case, remoteness is the only powerful instrument. It has the expected sign. In the last three columns, the first stage for the bilateral, multilateral, and trade structure variables are presented when we use the decade lumping procedure. In this case, all the instruments have the expected sign and are somewhat less powerful, although the $F$-tests still pass Staiger and Stock's (1997) threshold.

Table 7 shows the second stage of our instrumented regressions. Column (1) provides benchmark results for the non-instrumented regression on the sample where all country pairs involving donor countries are excluded. The results are close to those obtained with country pair fixed effects on the full sample-see regression (6) of Table 3. Column (2) shows the results for the instrumented regression where all trade variables have the right sign and are significant at the $1 \%$ level. While the coefficient for multilateral trade remains quite stable, the one for bilateral trade is quite different from its value found in the non-instrumented specification of column (1); this confirms our view that endogeneity bias and measurement error are more a source of concern for bilateral trade than for multilateral trade. In columns (3) and (4), we present the noninstrumented and the instrumented regressions, respectively, when the explanatory variable is the geographical structure of trade; results are similar and supportive of our predictions. In this case, 
TABLE 6

Impact of trade on wars-first-stage IV regressions

\begin{tabular}{|c|c|c|c|c|c|c|}
\hline & \multicolumn{6}{|c|}{ Dependent variable } \\
\hline & \multicolumn{3}{|c|}{ Yearly trade } & \multicolumn{3}{|c|}{ Average trade by decade } \\
\hline & $\begin{array}{c}\text { bil. } \\
\text { Model (a) }\end{array}$ & $\begin{array}{l}\text { mult. } \\
\text { Model (b) }\end{array}$ & $\begin{array}{l}\text { mul./bil. } \\
\text { Model (c) }\end{array}$ & $\begin{array}{c}\text { bil. } \\
\text { Model (d) }\end{array}$ & $\begin{array}{c}\text { mult. } \\
\text { Model (e) }\end{array}$ & $\begin{array}{l}\text { mul./bil. } \\
\text { Model (f) }\end{array}$ \\
\hline GSP IV & $\begin{array}{c}0.033 \\
(0.025)\end{array}$ & $\begin{array}{l}0.049 * * * \\
(0 \cdot 007)\end{array}$ & $\begin{array}{c}0 \cdot 016 \\
(0 \cdot 023)\end{array}$ & $\begin{array}{l}0.228 * * \\
(0 \cdot 131)\end{array}$ & $\begin{array}{l}0 \cdot 124 * * * \\
(0 \cdot 039)\end{array}$ & $\begin{array}{l}-0 \cdot 105 \\
(0 \cdot 110)\end{array}$ \\
\hline Remoteness IV & $\begin{array}{c}0.653 * * * \\
(0.033)\end{array}$ & $\begin{array}{c}0 \cdot 103 * * * \\
(0 \cdot 013)\end{array}$ & $\begin{array}{c}-0.550 * * * \\
(0.031)\end{array}$ & $\begin{array}{l}0.299 * * * \\
(0.066)\end{array}$ & $\begin{array}{c}-0.133 * * * \\
(0.026)\end{array}$ & $\begin{array}{l}-0.431 * * * \\
\quad(0.066)\end{array}$ \\
\hline Dummy for zero trade $t-4$ & $\begin{array}{c}-41.836 * * * \\
(0.014)\end{array}$ & $\begin{array}{c}-0.018 * * * \\
(0.004)\end{array}$ & $\begin{array}{l}1 \cdot 818 * * * \\
(0.014)\end{array}$ & $\begin{array}{l}-2.719 * * * \\
(0.049)\end{array}$ & $\begin{array}{c}-0.040 * * * \\
(0.015)\end{array}$ & $\begin{array}{c}2 \cdot 679 * * * \\
(0.049)\end{array}$ \\
\hline \# of peaceful years & $\begin{array}{c}-0.005 * * * \\
(0.001)\end{array}$ & $\begin{array}{c}-0.001 * * * \\
(0.000)\end{array}$ & $\begin{array}{c}0.004 * * * \\
(0.001)\end{array}$ & $\begin{array}{c}-0.009 * * * \\
(0.002)\end{array}$ & $\begin{array}{l}-0.001 \\
(0 \cdot 001)\end{array}$ & $\begin{array}{c}0.009 * * * \\
(0.002)\end{array}$ \\
\hline UN vote correlation & $\begin{array}{l}-0.015 \\
(0.021)\end{array}$ & $\begin{array}{c}-0.172 * * * \\
(0.008)\end{array}$ & $\begin{array}{c}-0.156 * * * \\
(0.021)\end{array}$ & & & \\
\hline Sum of democracy indexes & $\begin{array}{l}0.082 * * * \\
(0.014)\end{array}$ & $\begin{array}{l}0 \cdot 048 * * * \\
(0 \cdot 004)\end{array}$ & $\begin{array}{c}-0.034 * * \\
(0.013)\end{array}$ & $\begin{array}{l}0 \cdot 206 * * * \\
(0 \cdot 040)\end{array}$ & $\begin{array}{l}0 \cdot 147 * * * \\
(0 \cdot 014)\end{array}$ & $\begin{array}{l}-0.059 \\
(0.039)\end{array}$ \\
\hline \# other wars in $t$ & $\begin{array}{c}-0.013 * * * \\
(0.002)\end{array}$ & $\begin{array}{c}0 \cdot 001 \\
(0 \cdot 000)\end{array}$ & $\begin{array}{l}0 \cdot 014 * * * \\
(0 \cdot 002)\end{array}$ & $\begin{array}{c}-0.064 * * * \\
(0.008)\end{array}$ & $\begin{array}{l}-0.002 \\
(0.002)\end{array}$ & $\begin{array}{c}0.062 * * * \\
(0.007)\end{array}$ \\
\hline In distance to nearest war in $t$ & $\begin{array}{l}-0.003 \\
(0.008)\end{array}$ & $\begin{array}{c}-0.008 * * * \\
(0.002)\end{array}$ & $\begin{array}{l}-0.005 \\
(0.008)\end{array}$ & $\begin{array}{l}0.172 * * * \\
(0.036)\end{array}$ & $\begin{array}{c}0 \cdot 034 * * * \\
(0 \cdot 012)\end{array}$ & $\begin{array}{l}-0.138 * * * \\
\quad(0.036)\end{array}$ \\
\hline Alliance active in $t$ & $\begin{array}{c}0 \cdot 166 * * * \\
(0.034)\end{array}$ & $\begin{array}{c}0 \cdot 074 * * * \\
(0 \cdot 012)\end{array}$ & $\begin{array}{c}-0.092 * * * \\
(0.034)\end{array}$ & $\begin{array}{c}0.410 * * * \\
(0.097)\end{array}$ & $\begin{array}{l}0 \cdot 223 * * * \\
(0 \cdot 042)\end{array}$ & $\begin{array}{c}-0.187 * \\
(0.098)\end{array}$ \\
\hline \# of GATT members in pair & $\begin{array}{c}0 \cdot 169 * * * \\
(0 \cdot 011)\end{array}$ & $\begin{array}{l}0 \cdot 084 * * * \\
(0.003)\end{array}$ & $\begin{array}{c}-0.085 * * * \\
(0.011)\end{array}$ & $\begin{array}{c}0.043 \\
(0 \cdot 028)\end{array}$ & $\begin{array}{l}0 \cdot 077 * * * \\
(0 \cdot 010)\end{array}$ & $\begin{array}{c}0.034 \\
(0.028)\end{array}$ \\
\hline Free trade area (full set) & $\begin{array}{l}0.608 * * * \\
(0.023)\end{array}$ & $\begin{array}{c}0 \cdot 016 * * \\
(0 \cdot 007)\end{array}$ & $\begin{array}{c}-0.592 * * * \\
(0.023)\end{array}$ & $\begin{array}{c}1.152 * * * \\
(0 \cdot 070)\end{array}$ & $\begin{array}{l}-0 \cdot 025 \\
(0 \cdot 025)\end{array}$ & $\begin{array}{l}-1 \cdot 177 * * * \\
(0.069)\end{array}$ \\
\hline UN vote correlation & & & & $\begin{array}{c}0 \cdot 103 \\
(0 \cdot 070)\end{array}$ & $\begin{array}{l}-0.20 * * * \\
(0.027)\end{array}$ & $\begin{array}{c}-0.303^{* * *} \\
(0.068)\end{array}$ \\
\hline$F$-test on IVs & $197 \cdot 44$ & 61.92 & $156 \cdot 12$ & 11.93 & $16 \cdot 82$ & $22 \cdot 1$ \\
\hline Time dummies & Yes & Yes & Yes & Yes & Yes & Yes \\
\hline Dyadic war lags & Yes & Yes & Yes & Yes & Yes & Yes \\
\hline Dyadic same war lags & Yes & Yes & Yes & Yes & Yes & Yes \\
\hline$N$ & 161528 & 161528 & 161528 & 25034 & 25034 & 25034 \\
\hline Within- $R^{2}$ & $0 \cdot 194$ & $0 \cdot 189$ & $0 \cdot 189$ & $0 \cdot 323$ & 0.266 & $0 \cdot 319$ \\
\hline RMSE & $1 \cdot 249$ & $0 \cdot 361$ & $1 \cdot 239$ & $1 \cdot 025$ & $0 \cdot 371$ & $1 \cdot 004$ \\
\hline
\end{tabular}

Notes: S.E. in parentheses with ***,**, and *, respectively, denoting significance at the $1 \%, 5 \%$, and $10 \%$ levels. All columns show first-stage IV within estimates with dyadic fixed effect. All regressions (as in the second stage of IV estimation) include unreported time dummies, 20 lags of dyadic war, and 20 lags of dyadic same-war dummies. The first three columns present, respectively, results on bilateral trade, multilateral openness, and the trade structure ratio with annual variation. The last three columns present the same results when the variables are averaged by decade. Columns (a) and (b) present first-stage estimates of column (2) in Table 7. Columns (d) and (e) present first-stage estimates of column (6) in Table 7. Columns (c) and (f) present first-stage estimates of columns (4) and (8), respectively, in Table 7.

we can perform a Sargan test for overidentification; the test reveals a statistic of 0.001, which corresponds to a $P$-value of $0 \cdot 97$, stating that the exogeneity hypothesis on our instruments cannot be rejected. In the last four columns, we replicate the same exercise using the lumping procedure by decade. ${ }^{24}$ The results are remarkably stable and robust. All trade variables have the expected sign and are significant both in the benchmark regressions and in the IV ones. The usual rise in S.E. in IV estimates explains that the IV estimate for the multilateral trade variable is significant at the $10 \%$ level only. In terms of the Sargan overidentification test relative to the specification with trade structure in column (8), the statistic is 0.006 with a $P$-value of 0.94 comparable to the non-lumped case of column (4).

24. Those specifications with lumped variables (suggested by a referee) are extremely demanding because they include country pair fixed effects and therefore identify all coefficients along the time dimension which now has at most five observations by dyad (i.e. five decades). 


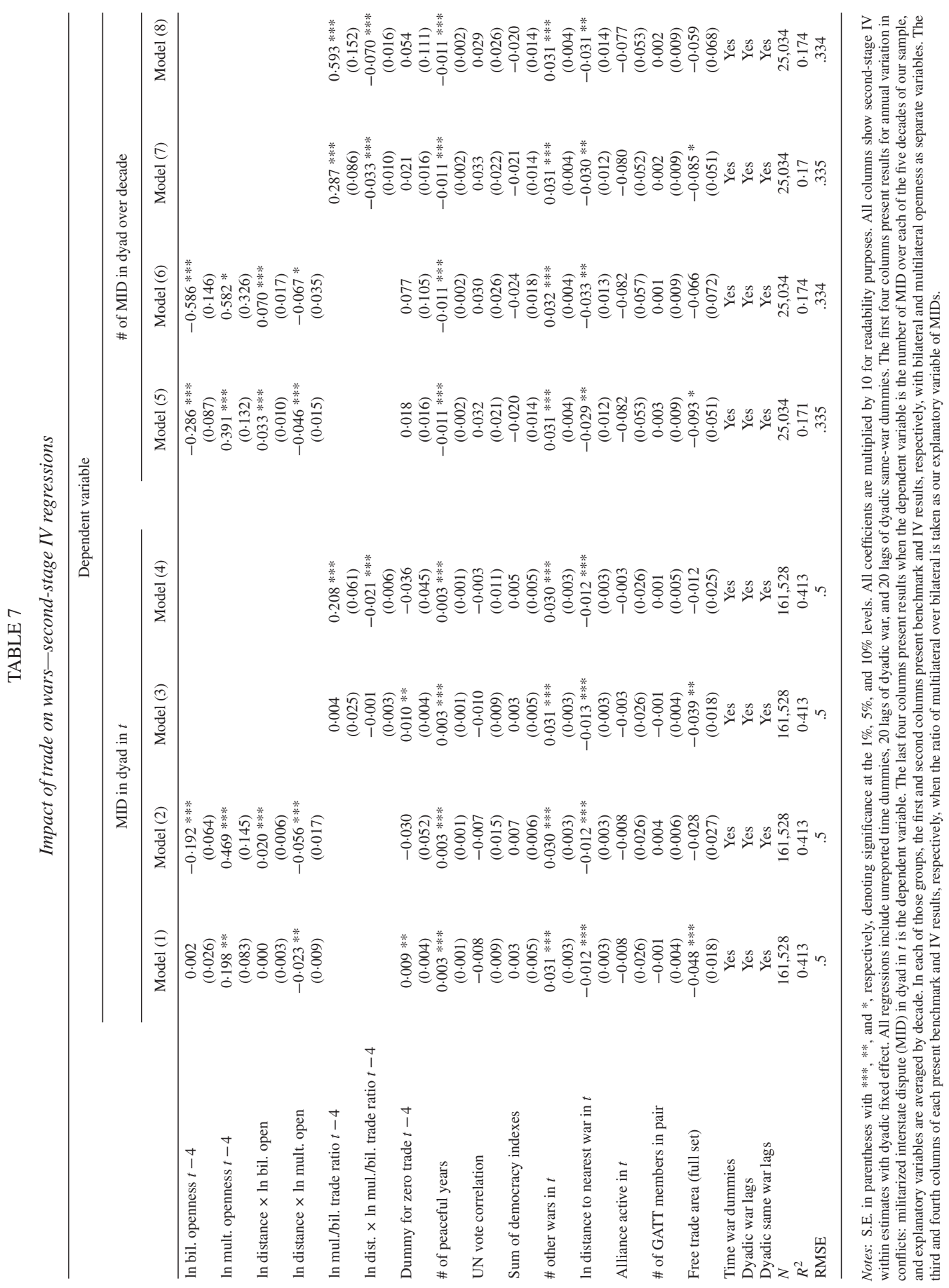




\section{CONCLUSIONS}

Our paper is the first, to our knowledge, to highlight the opposite effects of bilateral and multilateral trade on the probability of war and to base the empirical analysis on testable predictions generated by a theoretical model. We have shown that even in a model where trade increases welfare and war is Pareto dominated by peace, higher trade flows may not lead to more peaceful relations. Indeed, what matters ultimately is the geographical structure of trade and its balance between bilateral and multilateral openness. Bilateral trade, because it increases the opportunity cost of bilateral war, deters bilateral war. Multilateral trade openness, because it reduces this opportunity cost with any given country, weakens the incentive to make concessions during negotiations to avert escalation and therefore increases the probability of war between any given pair of country. From this point of view, an increase in trade between two countries pacifies relations between those but increases the probability of conflict with third countries. Our econometric analysis validates this prediction using a large number of alternative specifications and empirical strategies. Trade globalization also affects the nature of war: Multilateral openness increases the probability of local wars but should deter global conflicts. This last point, a logical consequence of our results but that we cannot test directly, is important. Given that these conflicts are certainly the most costly in terms of human welfare, this is not a small achievement.

Our model and empirical results also suggest that regional and bilateral trade agreements which foster regional and bilateral trade flows may have positive consequences for political relations. The positive political implications of these agreements may become even more important as multilateral trade flows increase. Hence, a possible extension is to focus on the impact of regional trade agreements on the probability of war and in particular to better understand which features of trade agreements are peace promoting. This could provide an assessment of whether regional trade agreement, allowing for an increase in regional trade, is enough to augment peace prospects or whether countries should be tied further by institutional and political ties. Other extensions include the impact of globalization on information flows and through this channel on the probability of war. A recent literature in trade (Rauch, 1999) has argued both theoretically and empirically that trade in differentiated products (as opposed to homogeneous products traded anonymously) should generate more interactions between traders and therefore more information flows. Hence, one could more precisely test the impact of trade on war through the information channel by following Rauch's distinction between differentiated and homogeneous products. A related extension would be to analyse the case where goods of different countries are complements rather than imperfect substitutes (e.g. in the case of intermediate inputs). This would change some results of the theoretical section as multilateral trade openness may in this case diminish the probability of escalation into a bilateral conflict. This possibility would need to be tested by distinguishing trade flows according to the degree of substituability of goods, and this would constitute an additional way to test the mechanisms at work in our story.

\section{APPENDIX A. SOLVING FOR THE SECOND BEST PROTOCOL}

This section derives the second best mechanism of our bargaining game under asymmetric information. To this purpose, we rely on Myerson-Satherwaite (denoted M-S) and provide a two-stage proof which follows Compte and Jehiel (2005). First, we study the equilibrium of a particular protocol, the so-called Nash bargaining protocol. We then show that this protocol implements the second best mechanism.

Remember that our setup differs from the M-S setup as (1) at any time, countries may quit negotiations and (2) private information is partially correlated between countries: the outside options are uniformly distributed on the triangle $\Gamma=\left(M, M_{A}, M_{B}\right)$ (see Figure 3$)$.

$$
\Gamma=\left\{\left(\tilde{U}_{i}^{W}, \tilde{U}_{j}^{W}\right) \mid\left(\tilde{U}_{i}^{W}, \tilde{U}_{j}^{W}\right) \geq\left(\underline{v_{i}}, \underline{v_{j}}\right) \text { and } \tilde{U}_{i}^{W}+\tilde{U}_{j}^{W} \leq \bar{v}\right\}
$$

(C) 2008 The Review of Economic Studies Limited 
with $\underline{v_{i}} \equiv(1-V / 2) U_{i}^{W}$ and $\underline{v_{j}} \equiv(1-V / 2) U_{j}^{W}$ and $\bar{v}=(1+V)\left(U_{i}^{W}+U_{j}^{W}\right)$. From assumption (1), peace Pareto dominates war, meaning that $\overline{\bar{v}}<S^{P} \equiv U_{i}^{P}+U_{j}^{P}$. In the rest of the section, for the sake of expositional clarity, we assume without loss of generality 25 that $V=2$ such that $\underline{v_{i}}=\underline{v_{j}}=0$.

\section{A.1. The Nash bargaining protocol}

The Nash bargaining protocol was first described in a slightly different setting by Chatterjee and Samuelson (1983). This is a two-stage protocol.

- Announcement stage: In the first stage, both countries $i$ and $j$ announce an outside option $\left(\hat{U}_{i}^{W}, \hat{U}_{j}^{W}\right)$, and a sharing rule is proposed.

If the announcements are compatible, that is, if the sum $\hat{U}_{i}^{W}+\hat{U}_{j}^{W} \leq S^{P}$, an agreement is proposed along with transfers $\tau_{i}\left(\hat{U}_{i}^{W}, \hat{U}_{j}^{W}\right)$ and $\tau_{j}\left(\hat{U}_{i}^{W}, \hat{U}_{j}^{W}\right)$ chosen so that each party obtains, in addition to its announced outside option, half the surplus $S^{P}-\left(\hat{U}_{i}^{W}+\hat{U}_{j}^{W}\right)$ that is:

$$
\tau_{i}\left(\hat{U}_{i}^{W}, \hat{U}_{j}^{W}\right)=\hat{U}_{i}^{W}+\frac{S^{P}-\left(\hat{U}_{i}^{W}+\hat{U}_{j}^{W}\right)}{2} \text { and } \tau_{j}\left(\hat{U}_{i}^{W}, \hat{U}_{j}^{W}\right)=\hat{U}_{j}^{W}+\frac{S^{P}-\left(\hat{U}_{i}^{W}+\hat{U}_{j}^{W}\right)}{2} .
$$

In case the announcements are not compatible, $\hat{U}_{i}^{W}+\hat{U}_{j}^{W}>S^{P}$, the bargaining process stops, war is triggered, and each party gets its (true) outside option $\left(\tilde{U}_{i}^{W}, \tilde{U}_{j}^{W}\right)$.

- Agreement stage: In the second stage, parties sequentially report if they accept the deal. ${ }^{26}$ If both parties say "yes," the deal is implemented. Otherwise, negotiation stops, war is triggered, and each party gets its (true) outside option $\left(\tilde{U}_{i}^{W}, \tilde{U}_{j}^{W}\right)$.

Clearly, in the second stage, it is a dominant strategy for each party $k \in(i, j)$ with true outside option $\tilde{U}_{k}^{W}$ to say "yes" (respectively, "no") if $\tau_{k} \geq \tilde{U}_{k}^{W}$ (respectively, $\tau_{k}<\tilde{U}_{k}^{W}$ ). From Compte and Jehiel (2005), we are able to characterize the equilibrium of the outside option announcement game: ${ }^{27}$

Lemma 1. At equilibrium, a party $k \in\{i, j\}$ with (true) type $\tilde{U}_{k}^{W}$ announces $\hat{U}_{k}^{W}=a\left(\tilde{U}_{k}^{W}\right)$, where

$$
a\left(\tilde{U}_{k}^{W}\right)=\frac{1}{4} S^{p}+\frac{2}{3} \tilde{U}_{k}^{W}
$$

Consequently, there is an agreement and peace is maintained when $\tilde{U}_{i}^{W}+\tilde{U}_{j}^{W} \leq \frac{3}{4} S^{P}$. War occurs for $\tilde{U}_{i}^{W}+\tilde{U}_{j}^{W}>$ $\frac{3}{4} S^{P}$. In Figure 3, disagreement arises for every couple of outside options which are located in the $A B M_{B} M_{A}$ dashed area.

Proof of Lemma 1. The expected gain of player $i$ with type $\tilde{U}_{i}^{W}$ when announcing $\hat{U}_{i}^{W}$ is

$$
\begin{aligned}
G\left(\tilde{U}_{i}^{W}, \hat{U}_{i}^{W}\right)= & \int \frac{S^{p}-\hat{U}_{i}^{W}+a\left(\tilde{U}_{j}^{W}\right)}{2}>\tilde{U}_{j}^{W} \max \left(\hat{U}_{i}^{W}, \frac{S^{p}-\hat{U}_{i}^{W}-a\left(\tilde{U}_{j}^{W}\right)}{2}\right) \frac{d \tilde{U}_{j}^{W}}{\bar{v}-\tilde{U}_{i}^{W}} \\
& +\tilde{U}_{i}^{W} \int \frac{S^{p}-\hat{U}_{i}^{W}+a\left(\tilde{U}_{j}^{W}\right)}{2}<\tilde{U}_{j}^{W} \frac{d \tilde{U}_{j}^{W}}{\bar{v}-\tilde{U}_{i}^{W}} .
\end{aligned}
$$

We now check that it is optimal for party $i$ to announce $\hat{U}_{i}^{W}=a\left(\tilde{U}_{i}^{W}\right)$. Given the form of $a(\cdot)$, it is readily verified that whenever the announcements are compatible, that is $a\left(\tilde{U}_{i}^{W}\right)+a\left(\tilde{U}_{j}^{W}\right)<S^{p}$, we have $a\left(\tilde{U}_{k}^{W}\right)>\tilde{U}_{k}^{W}$ for both

25. In Figure 3, assuming $V=2$ means that $M$ corresponds to the origin $(0,0)$.

26. This stage corresponds to our assumption of "no commitment protocol". In the original approach, this stage is not allowed: The parties agree ex ante on the sharing rule; they cannot ex post renegotiate.

27. In the general case of $V<2$, the formula becomes more complicated. Indeed, a straightforward variable change shows that in equilibrium, a party $k \in\{i, j\}$ with (true) type $\tilde{U}_{k}^{W}$ announces $\hat{U}_{k}^{W}=a\left(\tilde{U}_{k}^{W}\right)$, where $a\left(\tilde{U}_{k}^{W}\right)=\underline{v_{k}}+\frac{1}{4}\left(S^{p}-\right.$ $\left.\underline{v_{i}}-v_{j}\right)+\frac{2}{3}\left(\tilde{U}_{k}^{W}-\underline{v_{k}}\right)$. Consequently, there is an agreement and peace is maintained when $\left(\tilde{U}_{i}^{W}+\tilde{U}_{j}^{W}-\underline{v_{i}}-\underline{v_{j}}\right) \leq$ $\overline{\frac{3}{4}}\left(S^{P}-\underline{v_{i}}-\underline{v_{j}}\right)$. War occurs for $\left(\tilde{U}_{i}^{W}+\tilde{U}_{j}^{W}-\underline{v_{i}}-\underline{v_{j}}\right)>\frac{3}{4}\left(S^{P}-\underline{v_{i}}-\underline{v_{j}}\right)$.

(C) 2008 The Review of Economic Studies Limited 
$k \in\{i, j\}$. Hence, the Nash bargaining share of each party $k$ is above $\tilde{U}_{k}^{W}$. This allows to simplify the expression of $G\left(\tilde{U}_{i}^{W}, \hat{U}_{i}^{W}\right)$ when $\hat{U}_{i}^{W}$ lies in the neighbourhood of $a\left(\tilde{U}_{i}^{W}\right)$ in:

$$
\begin{aligned}
G\left(\tilde{U}_{i}^{W}, \hat{U}_{i}^{W}\right)= & \int a\left(\hat{U}_{j}^{W}\right)<S^{p}-\hat{U}_{i}^{W} \frac{S^{p}+\hat{U}_{i}^{W}-a\left(\hat{U}_{j}^{W}\right)}{2} \frac{d \tilde{U}_{j}^{W}}{\bar{v}-\tilde{U}_{i}^{W}} \\
& +\tilde{U}_{i}^{W} \int a\left(\hat{U}_{j}^{W}\right)>S^{p}-\hat{U}_{i}^{W} \frac{d \tilde{U}_{j}^{W}}{\bar{v}-\tilde{U}_{i}^{W}} .
\end{aligned}
$$

Differentiating $G\left(\tilde{U}_{i}^{W}, \hat{U}_{i}^{W}\right)$ with respect to $\hat{U}_{i}^{W}$ yields:

$$
\frac{\partial G\left(\tilde{U}_{i}^{W}, \hat{U}_{i}^{W}\right)}{\partial \hat{U}_{i}^{W}}=\frac{1}{\bar{v}-\tilde{U}_{i}^{W}}\left[\frac{b\left(S^{p}-\hat{U}_{i}^{W}\right)}{2}-\left(\hat{U}_{i}^{W}-\tilde{U}_{i}^{W}\right) b^{\prime}\left(S^{p}-\hat{U}_{i}^{W}\right)\right]
$$

where $b(x) \equiv-\frac{3}{8} S^{p}+\frac{3}{2} x$ is the inverse of function $a($.$) . Straightforward computations show that$

$$
\left.\frac{\partial G\left(\tilde{U}_{i}^{W}, \hat{U}_{i}^{W}\right)}{\partial \hat{U}_{i}^{W}}\right|_{\hat{U}_{i}^{W}=a\left(\tilde{U}_{i}^{W}\right)}=0 . \quad \|
$$

\section{A.2. Second best}

We now show that the Nash bargaining protocol described in the previous section implements the second best. From M-S (1983), we know that when outside options are uniformly distributed on the square $\left(\tilde{U}_{i}^{W}, \tilde{U}_{j}^{W}\right) \in\left[0, S^{p}\right] \times\left[0, S^{p}\right]$, the second best (requiring interim participation constraint but not an ex post one) is implemented by the Nash bargaining protocol and leads to an agreement whenever $\tilde{U}_{i}^{W}+\tilde{U}_{j}^{W} \leq \frac{3}{4} S^{P}$. But this is also the domain of agreement induced by the Nash bargaining protocol in our model where outside options are uniformly distributed on the triangle $\Gamma$ which can be viewed as a restriction of the uniform distribution to a subset of $\left[0, S^{p}\right] \times\left[0, S^{p}\right]$. This implies that the allocation resulting from the Nash bargaining protocol induces the second best in our particular setup.

Indeed by contradiction, assume that in our setup where outside options are uniformly distributed on the triangle $\Gamma$, there is a mechanism $\Omega$ that generates a strictly higher expected welfare than the Nash bargaining protocol. It would then be possible to improve upon the second best of the M-S setup, which we call the $M S$ mechanism. To this purpose, note that any "no commitment" truthful direct mechanism (i.e. satisfying the ex post participation constraints) is a truthful mechanism in the M-S setup (i.e. satisfying the interim participation constraint). Hence, in the M-S setup, we can build a mechanism $\Omega^{\prime}$ stipulating: for $\left(\tilde{U}_{i}^{W}, \tilde{U}_{j}^{W}\right) \in \Gamma$, we have $\Omega^{\prime}\left(\tilde{U}_{i}^{W}, \tilde{U}_{j}^{W}\right)=\Omega\left(\tilde{U}_{i}^{W}, \tilde{U}_{j}^{W}\right)$ and for $\left(\tilde{U}_{i}^{W}, \tilde{U}_{j}^{W}\right) \in\left[0, S^{p}\right]^{2}-\Gamma$, we have $\Omega^{\prime}\left(\tilde{U}_{i}^{W}, \tilde{U}_{j}^{W}\right)=\operatorname{MS}\left(\tilde{U}_{i}^{W}, \tilde{U}_{j}^{W}\right)$. From the previous remark, such a mechanism $\Omega^{\prime}$ is a truthful direct mechanism. Moreover as $\Omega$ generates a strictly higher expected welfare than the Nash bargaining protocol on $\Gamma$, we have that $\Omega^{\prime}$ generates a strictly higher expected welfare than the Nash bargaining protocol on the whole domain $\left[0, S^{p}\right] \times\left[0, S^{p}\right]$. But this is in contradiction with the fact that the Nash bargaining protocol is the second best for $\left(\tilde{U}_{i}^{W}, \tilde{U}_{j}^{W}\right)$ uniformly distributed on $\left[0, S^{p}\right] \times\left[0, S^{p}\right]$.

\section{APPENDIX B. EQUILIBRIUM VALUE OF THE PROBABILITY OF WAR}

Country $i$ 's welfare under peace is $U_{i}^{P}=U\left(x_{i}\right)$, where $x_{i} \equiv\left(\hat{L}_{i}, \hat{L}_{j}, T_{i j}, T_{i h}\right)$; under war, country $i$ 's welfare is stochastic (see equation (2)) but equal on average to an equilibrium value $U_{i}^{W}=U\left[\boldsymbol{x}_{i}(1-\Delta)\right]$ with $\Delta \equiv\left(\lambda, \lambda,-\tau_{\text {bil }},-\tau_{\text {multi }}\right)$. The probability of escalation to war between country $i$ and country $j$, given by equation (3), is then:

$$
\operatorname{Pr}\left(\text { escalation }_{i j}\right)=1-\frac{1}{4 V^{2}} \frac{\left[U\left(x_{i}\right)-U\left(x_{i}(1-\Delta)\right)+U\left(x_{j}\right)-U\left(x_{j}(1-\Delta)\right)\right]^{2}}{U\left(x_{i}(1-\Delta)\right) U\left(x_{j}(1-\Delta)\right)} .
$$

To obtain closed-form solutions, we assume that the two countries are identical (however, they may be different from the other countries in the world): $\boldsymbol{x}_{i}=\boldsymbol{x}_{j}$. We restrict our attention to first-order effects and use a Taylor expansion around an equilibrium where countries are identical, such that:

$$
\operatorname{Pr}\left(\text { escalation }_{i j}\right) \simeq 1-\frac{1}{V^{2}}\left[\Delta \frac{\nabla U\left(\boldsymbol{x}_{i}\right)}{U\left(\boldsymbol{x}_{i}\right)}\right]^{2},
$$


which can be rewritten, using equation (7) as equation (8) in the text with

$$
\begin{gathered}
W_{1} \equiv 1+\frac{1}{\sigma-1}\left(\frac{\hat{L}_{i}}{\sum_{h=1}^{R} \hat{L}_{h} T_{i h}^{1-\sigma}}+\frac{\hat{L}_{j} T_{i j}^{1-\sigma}}{\sum_{h=1}^{R} \hat{L}_{h} T_{i h}^{1-\sigma}}\right)=1+\frac{1}{\sigma-1}\left(\frac{m_{i i}}{E_{i}}+\frac{m_{i j}}{E_{i}}\right)>0 \\
W_{2} \equiv \frac{\hat{L}_{j} T_{i j}^{1-\sigma}}{\sum_{h=1}^{R} \hat{L}_{h} T_{i h}^{1-\sigma}}=\frac{m_{i j}}{E_{i}}>0 ; W_{3} \equiv \sum_{h \neq j, i}^{R} \frac{\hat{L}_{h} T_{i h}^{1-\sigma}}{\sum_{h=1}^{R} \hat{L}_{h} T_{i h}^{1-\sigma}}=\sum_{h \neq j, i}^{R} \frac{m_{i h}}{E_{i}}>0 .
\end{gathered}
$$

Using the national accounting identity: $\frac{m_{i i}}{E_{i}}+\frac{m_{i j}}{E_{i}}+\sum_{h \neq j, i}^{R} \frac{m_{i h}}{E_{i}}=1$, we obtain equation (9) in the text. Differentiating equation (8) with respect to $T_{i j}$ yields results mentioned in the text:

$$
\frac{d \operatorname{Pr}\left(1-\text { escalation }_{i j}\right)}{d\left(-T_{i j}\right)}=2 \operatorname{Pr}\left(1-\text { escalation }_{i j}\right)^{1 / 2} \frac{\sigma-1}{V} \frac{m_{i j}}{E_{i} T_{i j}}\left[\tau_{\text {bil }}\left(1-\frac{m_{i j}}{E_{i}}\right)+\left(\frac{\lambda}{\sigma-1}-\tau_{\text {multi }}\right) \sum_{h \neq j, i}^{R} \frac{m_{i h}}{E_{i}}\right] .
$$

Differentiating equation (8) with respect to $T_{i h}$ yields:

$$
\frac{d \operatorname{Pr}\left(1-\text { escalation }_{i j}\right)}{d\left(-T_{i h}\right)}=-2 \operatorname{Pr}\left(1-\text { escal }_{i h}\right)^{1 / 2} \frac{\sigma-1}{V} \frac{m_{i h}}{E_{i} T_{i h}}\left[\tau_{\text {bil }} \frac{m_{i j}}{E_{i}}+\left(\frac{\lambda}{\sigma-1}-\tau_{\text {multi }}\right)\left(1-\sum_{h \neq j, i}^{R} \frac{m_{i h}}{E_{i}}\right)\right]
$$

Using these two equations in the case of identical countries, we obtain the effect of globalization:

$$
\frac{d \operatorname{Pr}\left(1-\text { escalation }_{i j}\right)}{d(-T)}=-2 \operatorname{Pr}\left(1-\text { escalation }_{i j}\right)^{1 / 2} \frac{\sigma-1}{V} \frac{m_{i h} m_{i i}}{E_{i}^{2} T}(R-2)\left(\frac{\lambda}{\sigma-1}-\tau_{\text {multi }}-\frac{\tau_{\text {bil }}}{R-2}\right),
$$

which proves Result 1.

\section{APPENDIX C. EXAMPLES OF CONFLICTS}

Table A1 provides examples of representative conflicts that are classified as MIDs in our sample. For each hostility level, two cases with narratives from the COW project are presented.

\section{APPENDIX D. DATA SOURCES}

Bilateral trade is constructed from two different data sets. The first one is the data set assembled by Katherine Barbieri (see http://people.cas.sc.edu/barbierk/databases.html), which uses mostly information from the IMF since World War II and from the League of Nations international trade statistics and various other sources including individual countries before World War II. Her data spans over the 1870-1992 period. We completed it for the post-World War II period using the IMF DOTS database (the same primary source as Barbieri, 2002, for this period). Income data come from three different sources. We use in priority the Penn World Tables (6.2). These data are complemented by two different sources, Barbieri (2002), which assembles a data set for the 1948-1992 period, and the World Bank's WDI database for 1960-2000. Variables accounting for bilateral trade impediments or facilitating factors (distance, contiguity, and colonial links) come from the CEPII bilateral distance database (www.cepii.fr/anglaisgraph/bdd/distances.htm). On the same site can be found a data set of geographical characteristics of different countries used to obtained areas here. The dummy for regional trade agreements includes all agreements listed in Baier and Bergstrand (2004), each under their different time-varying membership configurations. GATT/WTO membership dates were obtained from the WTO web site (http://www.wto.org/). For GSP programmes, we use the data set of Rose (2004) made available on his web site.

Kimberly Ann Elliot generously provided data on trade sanctions constructed for the Elliot et al. (2005) study. For oil exporting countries, we follow the definition given by the IMF DOTS database. Communist regime spells come from the CIA world factbook. The primary goods export share of GDP comes from Sachs and Warner (2000) available at http://www.cid.harvard.edu/ciddata/ciddata.html.

The democracy index for each country comes from the Polity IV database, and we use the composite index that ranks each country on a -10 to +10 scale in terms of democratic institutions. We also use the correlation between countries' 
TABLE A1

Narratives of representative militarized interstate disputes (MIDs)

\begin{tabular}{lcl}
\hline Countries involved & Hostility level & Short narrative \\
\hline Guatemala/Belize & 3 & $\begin{array}{l}\text { 1993: Guatemala had long claimed the British colony of British } \\
\text { Honduras (Belize) to be Guatemalan territory. Guatemalan resi- } \\
\text { dents along the border claimed that Belizean soldiers made an in- } \\
\text { cursion to Guatemala and destroyed corn and rice crops. Belize } \\
\text { claimed that the soldiers were operating on Belizean soil. As a re- } \\
\text { sponse, the Guatemalan government dispatched } 60 \text { soldiers to the } \\
\text { disputed border. }\end{array}$
\end{tabular}

Togo/Ghana

1994: Togo claims an incursion of 100 fighters (irregulars) from Ghana and accuses Ghana of supporting rebels. Togo closes its border with Ghana based on this claim. Ghana denies any involvement and accuses Togo of aggression. This MID is the border closing by Togo.

Cameroun/Nigera

U.S./Iraq

Ethiopia/Eritrea
4

4

5

1995: Camerounian troops attacked a Nigerian post, captured it, and lost it later in a Nigerian counter-offensive.

The FBI determined that the Iraqi government undertook a plot to assassinate former President Bush when he visited Kuwait in mid-April, 1993. The Clinton administration retaliated by launching a cruise missile strike against an Iraqi intelligence facility in downtown Baghdad.

In May, 1998, border skirmishes between Ethiopia and Eritrea spun into the world's largest conventional war at the time. The war displaced hundreds of thousands of residents and claimed several thousands causalities. In June 2000, Ethiopia and Eritrea signed a cease-fire and a permanent peace treaty in December.

Jordan, Egypt, Syria, Iraq/Israel

1966-67: Six Day War Jordan, Egypt, Syria and Iraq against Israel

positions during votes on resolutions in the General Assembly of the United Nations as an index of their "political affinity." The UN votes correlation is based on the roll-call votes. This form of vote happens when one member state requests the recording of the vote so that its stand, or the stand of another member state, on the issue under discussion is clearly identified. This recording must be requested before the voting is conducted. This annual database, created by Gartzke et al. (1999), covers the 1946-1996 period. Military expenditures and alliances come from the COW project web site.

Acknowledgements. We thank the four anonymous referees and Fabrizio Zilibotti, the editor in charge of our paper. Very helpful comments were also provided by Daron Acemoglu, Harry Bowen, Martin Feldstein, Gregory Hess, Philippe Jehiel, Ethan Kapstein, Douglas Miller, Solomon Polachek, Robert Powell, Jean-Marc Robin, and Andy Rose. We also thank participants during presentations at the NBER Summer Institute, ERWIT (Rotterdam), the CEPR "Macroeconomics and war" conference (Barcelona), and seminars in Columbia, NYU, Princeton, Berkeley, UC Davis, Tel-Aviv, Jerusalem, Georgetown, LSE, Geneva, Stockholm, Cergy, Paris, IUE-Florence, INSEAD, UNCTAD, IMF, UCL, WTO, and New York Fed. Kimberly Ann Elliot kindly provided us the data on trade sanctions. All errors remain ours. Philippe Martin thanks Institut Universitaire de France, ANR, and Cepremap for financial assistance.

\section{REFERENCES}

AI, C. and NORTON, E. (2003), "Interaction Terms in Logit and Probit Models", Economics Letters, 80, 123-129.

ALESINA, A. and SPOLAORE, E. (1997), "On the Number and Size of Nations", Quarterly Journal of Economics, 112 (4), 1027-1056.

ALESINA, A. and SPOLAORE, E. (2003), The Size of Nations (Cambridge: MIT Press).

ALESINA, A. and SPOLAORE, E. (2005), "War, Peace and the Size of Nations", Journal of Public Economics, 89 (7), $1333-1354$.

ALESINA, A. and SPOLAORE, E. (2006), "Conflict, Defense Spending and the Number of Nations", European Economic Review, $\mathbf{5 0}$ (1), 91-120.

ANDERSON, J. and VAN WINCOOP, E. (2004), “Trade Costs”, Journal of Economic Literature, XLII, 691-751.

(C) 2008 The Review of Economic Studies Limited 
ANDERTON, C. and CARTER, J. R. (2001), “The Impact of War on Trade: An Interrupted Times-Series Study”, Journal of Peace Research, 38 (4), 445-457.

BAIER, S. and BERGSTRAND, J. (2004), "Economic Determinants of Free Trade Agreements", Journal of International Economics, 64, 29-63.

BALDWIN, R. and MURRAY, T. (1977), "MFN Tariff Reductions and Developing Country Trade Benefits Under the GSP”, Economic Journal, 87, 30-46.

BARBIERI, K. (1996), "Economic Interdependence: A Path to Peace or a Source of Interstate Conflict?", Journal of Peace Research, 33 (1), 29-49.

BARBIERI, K. (2002), The Liberal Illusion, Does Trade Promote Peace? (Ann Arbor: The University of Michigan Press).

BARBIERI, K. and SCHNEIDER, G. (1999), "Globalization and Peace: Assessing New Directions in the Study of Trade and Conflict", Journal of Peace Research, 36 (4), Special Issue on Trade and Conflict, 387-404.

BLOMBERG, S. and HESS, G. (2006), "How Much Does Violence Tax Trade?", Review of Economics and Statistics, 88 (4), 599-612.

BOND, B. (1986), War and Society in Europe, 1870-1970 (New York: Oxford University Press).

BRODA, C. and WEINSTEIN, D. (2006), "Globalization and the Gains from Variety", Quarterly Journal of Economics, 121 (2), 541-585.

CAMERON, A. C., GELBACH, J. B. and MILLER, D. L. (2006), "Robust Inference with Multi-Way Clustering” (NBER Technical Working Paper No. 327).

CHATTERJEE, K. and SAMUELSON, W. (1983), "Bargaining under Incomplete Information”, Operations Research, 31, 835-851.

COMPTE, O. and JEHIEL, P. (2005), "Inefficiencies in Bargaining: Departing from Akerlof and Myerson-Satterthwaite" (Mimeo, CERAS).

CREMER, J. and Mc LEAN, R. (1988), "Full Extraction of the Surplus in Bayesian and Dominant Strategy Auctions", Econometrica, 56, 1247-1257.

ELliOT, K., SCHOTT, J., HUFBAUER, G. and OEGG, B. (2005), Economic Sanctions Reconsidered, 3rd edn (Washington DC: Institute for International Economics).

FATEN, G., PALMER G. and BREMER, S. (2004), “The MID3 Data Set, 1993-2001: Procedures, Coding Rules, and Description", Conflict Management and Peace Science, 21, 133-154.

FEARON, J. (1995), "Rationalist Explanations for War”, International Organization, 49 (3), 379-414.

GARFINKEL, M. (1994), "Domestic Politics and International Conflict", American Economic Review, 84 (5), 1294 1309.

GLICK, R. and TAYLOR, A. (2005), "Collateral Damage: Trade Disruption and the Economic Impact of War" (National Bureau of Economic Research Working Paper No. 11565).

GROSSMAN, H. (2003), "Choosing Between Peace and War" (National Bureau of Economic Research Working Paper No. 10180).

HEAD, K. and RIES, J. (2001), "Increasing Returns versus National Product Differentiation as an Explanation for the Pattern of U.S.-Canada Trade", American Economic Review, 91 (4), 858-876.

HESS, G. (2004), "The Economic Welfare Cost of Conflict: An Empirical Assessment" (Working Paper 08, Claremont Mc Kenna College).

HESS, G. and ORPHANIDES, A. (1995), "War Politics: An Economic, Rational-Voter Framework", American Economic Review, 85 (4), 828-846.

HESS, G. and ORPHANIDES, A. (2001), "War and Democracy", Journal of Political Economy, 109 (4), 776-810.

JONES, D., BREMER, S. and SINGER, D. (1996), "Militarized Interstate Disputes, 1816-1992: Rationale, Coding Rules and Empirical Patterns", Conflict Management and Peace Science, 15 (2), 163-212.

KAPSTEIN, E. (2003), "Two Dismal Sciences Are Better Than One-Economics and the Study of National Security, A Review Essay”. International Security, 27 (3), 158-187.

KEEGAN, J. (1984), A History of Warfare (New York: Vintage).

KOCS, S. (1995), “Territorial Disputes and Interstate War”, Journal of Politics, 57 (1), 159-175.

LEVY, G. and RAZIN, R. (2004), "It Takes Two: An Explanation for the Democratic Peace", Journal of the European Economic Association, 2 (1), 1-29.

MADDISON, A. (2001), The World Economy: Historical Statistics (Paris: OECD).

MANSFIELD, E. (1995), Power, Trade, and War (Princeton: Princeton University Press).

MORROW, J., SIVERSON, R. and TABARES, T. (1998), “The Political Determinants of International Trade: The Major Powers, 1907-90", American Political Science Review, 92 (3), 649-661.

MYERSON, R. and SATTERTHWAITE, M. (1983), "Efficient Mechanisms for Bilateral Trading", Journal of Economic Theory, 29, 265-281.

ONEAL, J. and RUSSETT, B. (1999), "Assessing the Liberal Peace with Alternative Specifications: Trade Still Reduces Conflict”, Journal of Peace Research, 36 (4), Special Issue on Trade and Conflict, 423-442.

POLACHEK, S. (1980), "Conflict and Trade”, Journal of Conflict Resolution, 24 (1), 57-78.

POLACHEK, S., ROBST, J. and CHANG, Y.-C. (1999), "Liberalism and Interdependence: Extending the Trade-Conflict Model", Journal of Peace Research, 36 (4), Special Issue on Trade and Conflict, 405-422.

POWELL, R. (1999), In the Shadow of Power: States and Strategies in International Politics (Princeton: Princeton University Press).

RAUCH, J. (1999), “Networks versus Markets in International Trade”, Journal of International Economics, 48 (1), 7-35. 
ROMALIS, J. (2003), "Would Rich Country Trade Preferences Help Poor Countries Grow? Evidence from the Generalized System of Preferences" (Mimeo, Chicago GSB).

ROSE, A. (2004), "Do We Really Know That the WTO Increases Trade?", American Economic Review, 94 (1), $98-114$.

SACHS, J. and WARNER, A. (2000), "Natural Resource Abundance and Economic Growth", in G. Meier and J. Rauch (eds.) Leading Issues in Economic Development (New York: Oxford University Press) 161-167.

SCHNEIDER, G. and SCHULZE, G. (2005), "Trade and Armed Conflict: The Domestic Foundations of Commercial Liberalism" (Mimeo, University of Konstanz).

SKAPERDAS, S. and SYROPOULOS, C. (2001), "Guns, Butter, and Openness: On the Relationship Between Security and Trade", American Economic Review, Papers and Proceedings, 91 (2), 353-357.

SKAPERDAS, S. and SYROPOULOS, C. (2002), "Insecure Property and the Efficiency of Exchange," Economic Journal, 112, 133-146.

STAIGER, D. and STOCK, J. (1997), "Instrumental Variables Regression with Weak Instruments", Econometrica, 65 (3), 557-586.

UNCTAD (2003), "Trade Preferences for LDCs: An Early Assessment of Benefits and Possible Improvements".

VAN CREVELD, M. (1991), The Transformation of War (New York: The Free Press).

YILDIZ, M. (2004), "Waiting to Persuade", Quarterly Journal of Economics, 119 (1), 223-248.

WOOLDRIDGE, J. (2002), Econometric Analysis of Cross Section and Panel Data (Cambridge, MA: MIT Press). 